\title{
The Effects of Expertise and Demographic Characteristics on Public Administrators' Attitudes to E-government
}

\author{
Raji Msail AISharari \\ West Virginia University
}

Follow this and additional works at: https://researchrepository.wvu.edu/etd

\section{Recommended Citation}

AlSharari, Raji Msail, "The Effects of Expertise and Demographic Characteristics on Public Administrators' Attitudes to E-government" (2011). Graduate Theses, Dissertations, and Problem Reports. 4685.

https://researchrepository.wvu.edu/etd/4685

This Dissertation is protected by copyright and/or related rights. It has been brought to you by the The Research Repository @ WVU with permission from the rights-holder(s). You are free to use this Dissertation in any way that is permitted by the copyright and related rights legislation that applies to your use. For other uses you must obtain permission from the rights-holder(s) directly, unless additional rights are indicated by a Creative Commons license in the record and/ or on the work itself. This Dissertation has been accepted for inclusion in WVU Graduate Theses, Dissertations, and Problem Reports collection by an authorized administrator of The Research Repository @ WVU.

For more information, please contact researchrepository@mail.wvu.edu. 
The Effects of Expertise and Demographic Characteristics on Public Administrators' Attitudes to E-government

\title{
Raji Msail AlSharari
}

\author{
Dissertation submitted to the \\ College of Human Resources and Education \\ at West Virginia University \\ in partial fulfillment of the requirements \\ for the degree of
}

\author{
Doctor of Education \\ in \\ Curriculum and Instruction \\ Patricia Obenauf, Ed.D, Chair \\ Perry Phillips, Ed.D. \\ David Callejo, Ed.D. \\ Ernest Goeres, Ph.D. \\ Mohamed Alkadry, Ph.D. \\ James Nolan, Ph.D
}

Department of Curriculum and Instruction/Literacy Studies

Morgantown, West Virginia

2011

Keywords: E-government, E-technology, Public Administration, Expertise, Attitude Copyright 2011 Raji Msail AlSharari 


\section{Abstract \\ The Effects of Expertise and Demographic Characteristics on Public Administrators' Attitudes to E-government}

\section{Raji Msail AlSharari}

Due to recent advancements in electronic technology (e-technology), research on the developing field has become important for understanding how this technology affects the population and how the population affects this technology. Research on etechnology reveals that demographic characteristics (age, gender, location, and education) and expertise are factors affecting e-technology attitudes and performance. One of the emerging e-technology fields is electronic government (e-government). After reviewing historical research in e-technology, this study reviewed existing egovernment literature to determine key obstacles for public administrators to implement e-government. This study used a survey questionnaire, based on egovernment attitude surveys conducted by Moon (2002) and Moon and Welch (2005), to determine attitudes of 660 randomly selected city and county public administrators chosen from an International City/County Management Association (ICMA) mailing list. A sample of 10 randomly selected city and county administrators was also chosen from an ICMA list as a pilot study to create reliability and validity for the egovernment attitude survey. Both quantitative and qualitative forms of statistical analysis were used to analyze the collected survey data. These results provided an exploratory analysis of differences in public administrator attitudes that could be used to find understanding within public administrator discourse communities or to further future research into methods of resolving these differences. 
E-government Attitudes iii

\section{Dedication}

I dedicate this to my parents, Msail and Hamdah, who have constantly supported me and encouraged me in all aspects of my life. 


\section{Acknowledgements}

First, and foremost, I want to thank ALLAH, the Most Gracious, the Most Merciful, who guided me to this path and without the guidance from ALLAH, this would not have been possible. I want to also thank my parents, Msail and Hamdah, and my entire family for supporting me throughout this process.

I would like to thank all my committee members: Dr. Patricia Obenauf, Dr. Perry Phillips, Dr. David Callejo, Dr. Ernest Goeres, Dr.Mohamed Alkadry, and Dr. James Nolan. Dr. Obenauf, thank you for your kindness and patience during my research. Without your help, this would have been a much more difficult journey for me. Dr. Phillips, I truly appreciate your friendship and guidance, I will always remember how you have helped me during my studies. Dr. Callejo, I want to thank you for making me see the positive and constantly encouraging me to finish my dissertation. Dr. Alkadry, thank you for your expertise and guidance during this process. And, Dr. Nolan, I am truly grateful for your friendship and appreciate all your help and expertise you have given me during my research.

I must also thank my government in Saudi Arabia as well as the Institute of Public Administration who have granted me this opportunity to study in the United States to complete my studies. I feel very fortunate to be given this chance and I will always be grateful for such an opportunity.

Finally, a special thanks goes out to all the participants who took part in my study. I appreciate that they took the extra time from their busy schedules to aid me in my research data. 


\section{Table of Contents}

\section{Chapter 1: Introduction}

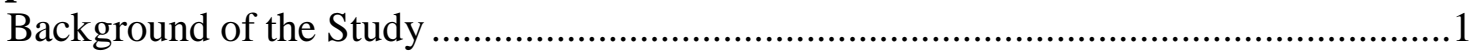

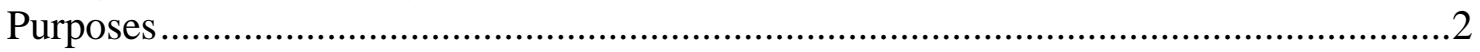

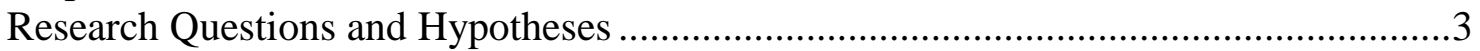

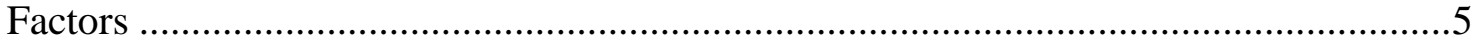

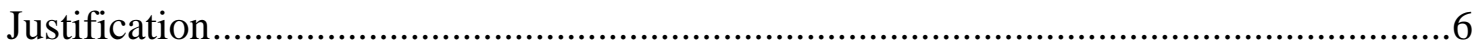

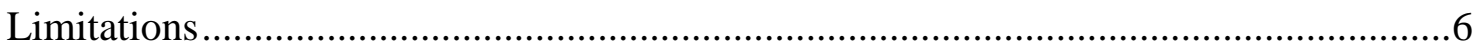

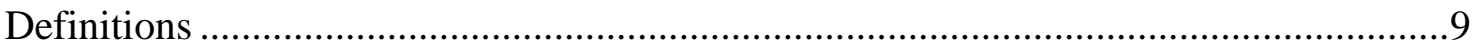

Chapter 2: Review of Literature

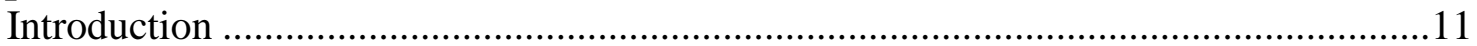

The Importance of Generational Research ............................................................. 13

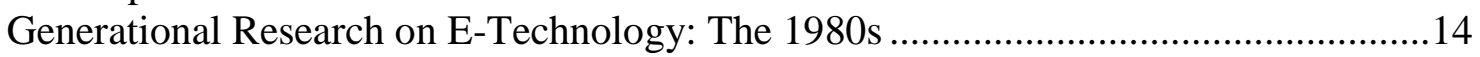

Generational Research on E-Technology: The 1990s ............................................18

Generational Research on E-Technology: The 2000 to the present ...........................23

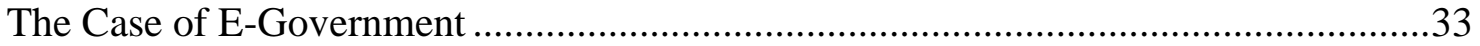

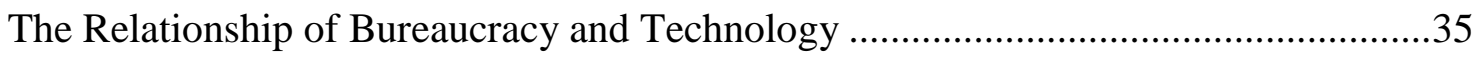

Lack of Standardization in Prevous E-Government Studies .......................................36

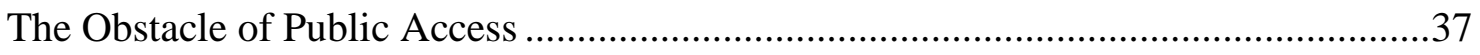

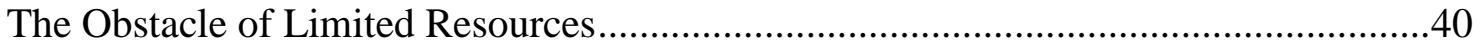

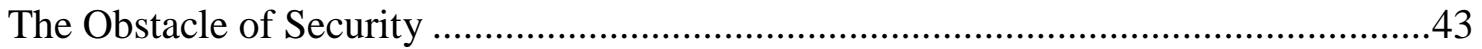

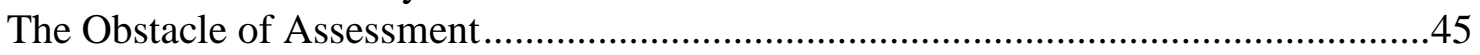

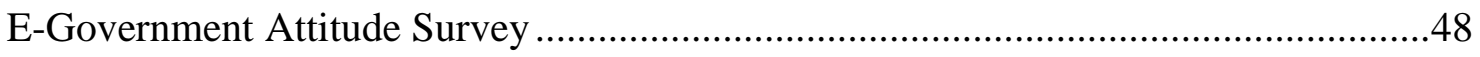

Conclusion and Recommendations for Future Research..........................................49

Chapter 3: Methodology

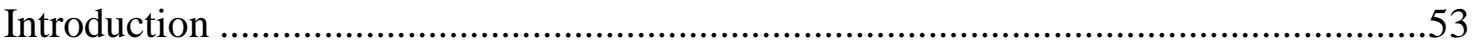

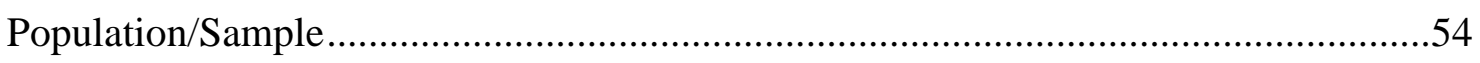

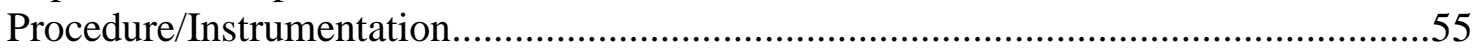

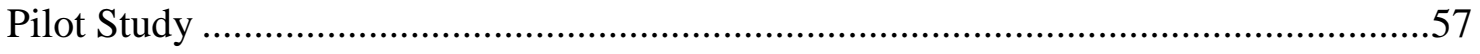

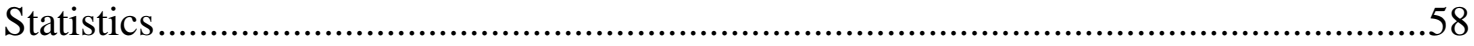

Chapter 4: Analysis of Data

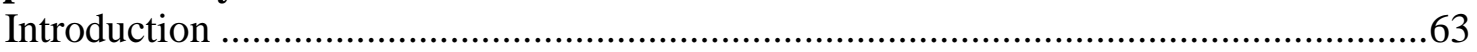

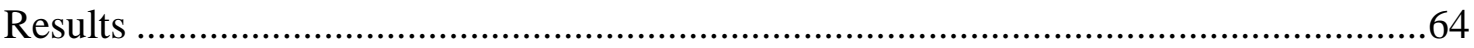

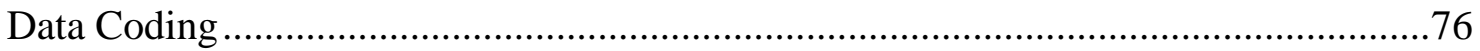

Chapter 5: Summary, Discussion, and Conclusion

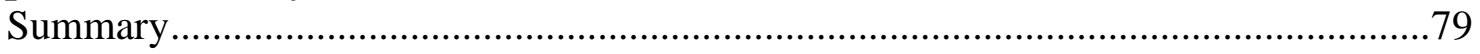

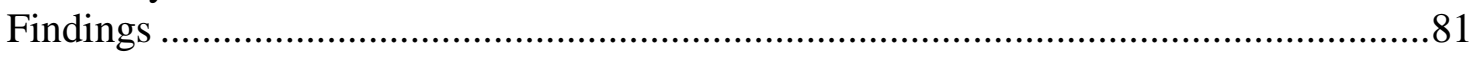

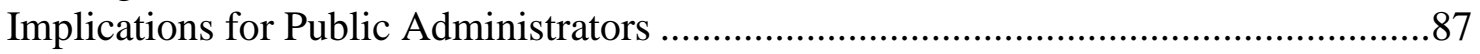

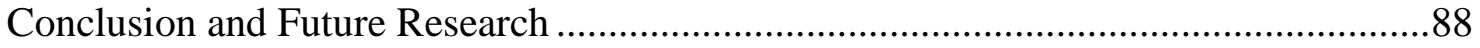

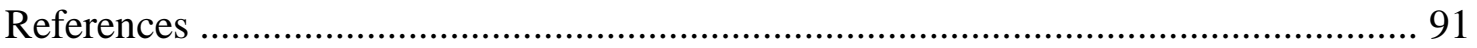

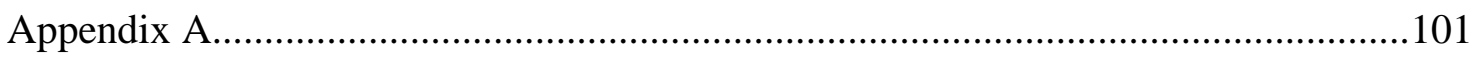

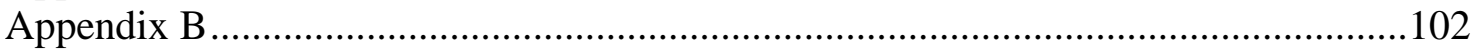

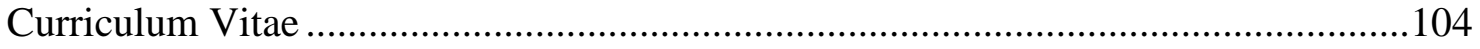


Chapter 1: Introduction

\section{Background of the Study}

The past twenty years have seen an increase in electronic technology (etechnology) throughout the world. This technology revolution is changing all aspects of modern life such as education with e-learning, business with e-commerce, and even government with e-government. However, the recent occurrence of this rise in technology has presented some problems. One of the main issues researchers have studied is the effect of generational gaps that divide the performance and attitudes of the population regarding e-technology. As these researchers have studied these generational gaps, they have also observed the potential for expertise as a moderating variable that could diminish the effect of age on e-technology attitudes and performance.

One of the newest e-technology fields to arise is the field of e-government. The research in this field is still developing, and there is a need for exploratory attitude surveys and case studies to help focus research in the field on the issues that influence egovernment. After a chronological review of the literature regarding generational research in e-technology, this study reviews the existing research on the key obstacles that public administrators face as they implement e-government. Then this study proposes an attitude survey for public administrators to determine the effect of the independent variables of age, gender, location, and education with the factor of expertise on their attitudes toward e-government, particularly with regard to their attitudes regarding key obstacles that have been determined by the literature review but also including an opportunity for written suggestions from the participants. 


\section{Purposes}

With the increasing implementation of technology in many fields, government still has not completely adopted electronic technology as a means of administrating local governments. Research is needed which focuses on analyzing the delayed acceptance of technology in government. This study has three main goals: to determine the effects of demographic characteristics and the factor of expertise on general attitudes to egovernment, to determine the effects of expertise on participants' evaluations of the main obstacles identified in the review of literature, and to allow participants to also provide written suggestions about the obstacles to e-government. The first goal of this study is to examine the main effects of the independent variables of age, gender, location, and education as well as the moderating factor of expertise and the interaction of the factor of expertise with the independent variables of age, gender, location, and education on public administrators' attitudes to e-government. The second goal of this study is to examine the effect of expertise on participants' perceptions of the obstacles to e-government identified in the literature review in order to determine whether differences in expertise cause different evaluations of e-government obstacles. The final goal of this study is to allow for an exploratory investigation into participants' perceived obstacles to e-government by providing a space for them to write any obstacles that they have personally observed.

This study proposes that research into differences in administrator attitudes could not only help administrators to understand differences that exist in their discourse community, but also help future researchers to focus on methods of reducing any gaps that are shown to exist among the administrators' attitudes, perceptions to obstacles based on expertise, and personally observed obstacles from the participants that may provide 
additional information about the difficulties of e-government implementation. This study intends to add to the field of generational research on e-technology and e-government by conducting a study within the population of public administrators on e-government based on previous generational research methods that have used attitude studies to examine differences in the population regarding e-technology. This study adapts e-government attitude surveys used by Moon (2002) and Moon and Welch (2005) that defined egovernment technologies and examined differences in attitudes toward e-government of citizens and bureaucrats and modifies those previous surveys to focus only on the attitudes of the bureaucrats, respectively. In addition, the key obstacles to e-government implementation in the latter attitude survey have been changed to match the issues identified as key obstacles to e-government in this review of the literature.

\section{Research Questions and Hypotheses}

This study consists of five research questions and fourteen null hypotheses. The first four research questions are evaluated using quantitative research methods, and the final research question is explored using qualitative research methods. For further details about the statistical methods of analysis, see Chapter 3: Methodology. Here is a list of the research questions and the hypotheses addressed in this study:

Question1: Is there an effect of e-technology expertise on public administrators' attitudes to e-government in general?

$\mathrm{H}_{\mathrm{O} 1}$ : There is no main effect for the factor of expertise (A) on attitudes to e-government. Question 2: Are there effects of demographic characteristics (age, gender, location, and education) on public administrator's attitudes to e-government in general? $\mathrm{H}_{\mathrm{O} 2}$ : There is no main effect for the factor of age (B) on attitudes to e-government. 
$\mathrm{H}_{\mathrm{O} 3}$ : There is no main effect for the factor of gender (C) on attitudes to e-government.

$\mathrm{H}_{\mathrm{O} 4}$ : There is no main effect for the factor of location (D) on attitudes to e-government. $\mathrm{H}_{05}$ : There is no main effect for the factor of education (E) on attitudes to e-government. Question 3: Are there effects of the interactions of expertise with demographic characteristics (age, gender, location, and education) on public administrator's attitudes to e-government in general?

$\mathrm{H}_{\mathrm{O} 6}$ : There is no interaction effect for the factors of expertise and age (AB) on attitudes to e-government.

$\mathrm{H}_{\mathrm{O} 7}$ : There is no interaction effect for the factors of expertise and gender (AC) on attitudes to e-government.

$\mathrm{H}_{\mathrm{O} 8}$ : There is no interaction effect for the factors of expertise and location (AD) on attitudes to e-government.

$\mathrm{H}_{09}$ : There is no interaction effect for the factors of expertise and education (AE) on attitudes to e-government.

Question 4: Are there effects of e-technology expertise on public administrators' perceptions of the potential obstacles to e-government identified in the review of literature?

$\mathrm{H}_{10}$ : There is no main effect for the factor of expertise (A) on public administrators' perceptions of the obstacle of resources to e-government. $\mathrm{H}_{11}$ : There is no main effect for the factor of expertise (A) on public administrators' perceptions of the obstacle of public access to e-government. $\mathrm{H}_{12}$ : There is no main effect for the factor of expertise (A) on public administrators' perceptions of the obstacle of security to e-government. 
$\mathrm{H}_{13}$ : There is no main effect for the factor of expertise (A) on public administrators' perceptions of the obstacle of assessments to e-government.

$\mathrm{H}_{14}$ : There is no main effect for the factor of expertise (A) on public administrators' perceptions of the obstacle of training to e-government.

Question 5: What items do public administrators list as potential obstacles to egovernment at this time?

Factors

This study contains four independent variables (age, gender, location, and education), one factor (expertise), and one dependent variable (attitudes to e-government). The independent variable of age is operationalized in two groups (Over 50 and 50 and younger). These were chosen in order to create generational groups that could be compared to observe any potential generational differences that exist in attitudes to egovernment. The independent variable of gender is operationalized in two nominal choices (female and male). The independent variable of location is operationalized in two nominal choices (city and county). The independent variable of education is operationalized in three nominal choices (Some college, College degree, and Graduate degree). The factor of expertise is also operationalized in three groups (Beginner, Intermediate, and Advanced) and includes technologies specific to e-government, based on a list of e-government technologies indicated by Moon (2002). Expertise is not evaluated through a testing of the participant's abilities because this study is a subjective attitude survey.

The dependent variable of attitudes to e-government is operationalized by an egovernment attitude scale that consists of two parts: general attitudes to e-government 
and perceptions of potential obstacles to e-government that have been identified in the literature review (limited resources, public access, security, proper assessment, and training). Both of these portions of the e-government attitude scale are provided through the survey questionnaire (see Appendix B). Additionally, this survey includes a section that allows for participants to provide obstacles that they have seen to the implementation of e-government, and the results of a qualitative analysis of this data are compared with the obstacles identified in the review of the literature.

\section{Justification}

This study is important because it continues methods of generational research on e-technology by using an attitude survey to understand differences that exist in the population. In addition, this study contributes to the developing field of e-government research by proposing a study on a comparison of administrator attitudes that has not previously been examined; specifically focusing on the main obstacles to the introduction of e-government by public administrators as compiled from a review of the literature, and the results of this study could help administrators to understand obstacles that exist within their discourse community as revealed by their attitude differences. In addition, due to the developing nature of this field of research, participants also have the opportunity to list any obstacles to e-government that they have observed in order to help further refine research in this field in the future.

\section{Limitations}

One of the major limitations of this study is the lack of existing research on egovernment. The literature review in this study examines the research to elicit the key obstacles that public administrators face as they introduce technology to government, but 
due to the lack of standardization in the previous e-government research, only the most important factors that occurred in the most studies are included as key obstacles. Another limitation is the use of self-described expertise and attitudes of the participants, and this data is highly subjective. This expertise is also limited to e-technology expertise and does not consider the expertise of the administrator in their position; thus, tenure and experience as an administrator have been removed from this survey for the purpose of focusing only on demographic characteristics and expertise with e-technology as potential influences on e-government attitudes. This limitation is due to the fact that this study is exploratory in nature and relies on self-evaluations to provide evidence that can be used for understanding differences in e-technology attitudes and for future research in the field of e-government.

Another limitation to this study is that the statistical analyses focuses on specific demographic information found in the literature review (age, gender, location, and education) and does not include all possible demographic characteristics. Furthermore, the literature review in this study shows the potential effect of expertise as a moderating factor on the effect of demographic characteristics on e-technology attitudes and performance, and this study only focuses on the interaction of the factor of expertise with the demographic characteristics rather than the interactions of all of the demographic characteristics with one another.

Also, the use of Moon's (2002) definition of e-government technologies may not be comprehensive enough to manifest the actual expertise of the participants. There is no comprehensive list of e-government technologies, but the list created by Moon (2002) seems to cover most of the important types of technologies that relate to e-government 
technologies being used at this time. This list has been broken down into the composite technologies that represent each of Moon's technology areas, but, again, this break-down is a limitation because it may be unevenly distributed or lacking in specific technologies that are important to e-technology expertise. Perhaps another list of e-government technologies could be used to better define the expertise of the participants, but for this study, the list created by Moon (2002) represents a sampling of the important technologies that are related to e-government.

Another limitation to this study involves the analysis of the factor of expertise to the potential obstacles to e-government identified in the literature review. Again, this analysis does not include all possible factors that could influence a public administrator's perceptions of those obstacles. However, due to the fact that expertise is shown in the literature review to be a factor that can change attitudes and performance with etechnology, this factor is used to determine whether differences in expertise with etechnology cause differences in perceptions toward the potential obstacles to egovernment.

The final limitation of this study is the fact that this study is limited to public administrators who are members of the International City/County Management Association (ICMA) because the participants in this study as well as the pilot study were chosen from an ICMA mailing list. It was unknown how the use of this organization affects the data, but a possible limitation could be the exclusion of participants who would be important administrators for the purposes of this study but are not members of this organization. 


\section{Definitions}

1. E-technology - E-technology is defined as any electronic technology such as computers, grocery store scanners, telephones, automated teller machines, electronic fund transfers, and the Internet.

2. E-government - E-government is defined as the use of e-technology to facilitate government services. For the purpose of the survey used in this study, the technologies which are specific to e-government are defined by Moon (2002) as electronic data interchange, interactive voice response, voicemail, e-mail, web service delivery, virtual reality, and public key infrastructure. These technology areas have been further broken down into their composite technologies in order to make them more accessible for the participants to understand. For a list of these technologies, see Appendix B.

3. Generation - Different studies use varying definitions for generational groups. For the purposes of this study, age is divided into two generational groups: over 50 years of age and 50 years of age and younger. In this study it is referred to as the digital divide.

4. Expertise - Expertise is defined in this study as expertise with e-technology through self-evaluation in the survey attached in Appendix B. For the purposes of this study, expertise is operationalized in three nominal categories (Beginner, Intermediate, and Advanced) according to the e-government technologies that were based on a list provided by Moon (2002).

5. Attitudes - Views toward e-government are defined through the survey that is attached in Appendix B. This E-government Attitude scale is created by the 
author based on a survey used by Welch and Moon (2005). Validity and reliability for the instrument are provided through the conduction of a pilot study. For more information about the pilot, see Chapter 3 of this study.

6. Obstacles - Barriers to e-government implementation are those issues which create difficulties for administrators to integrate e-technology and government. This study focuses on five main obstacles to e-government: public access, security, limited resources, proper assessment, and training. The four main obstacles identified by the e-government section of the literature review are public access, security, limited resources, and proper assessment, and training is included as a potential obstacle to e-government due to its importance as an obstacle to etechnology in general as identified by the generational research section of the literature review. In addition, this survey allows for participants to identify their own obstacles to e-government by providing a list at the end of the survey.

7. Demographic characteristics - Due to the factors shown in the literature review, demographic characteristics in this study are defined as age, gender, location, and education.

8. Municipality- In this study, two types of administration are considered within the factor of location. These two types of administration are municipality and county. In more general terms, municipality refers to the city level of government. 


\section{Chapter 2: Review of Literature}

\section{Introduction}

The recent growth of e-technology is revolutionizing societies around the world, and some experts, such as technology analyst Eric Lundquist (2007), state that there is a technology "renaissance" occurring and that it is just starting. Due to the recent innovation of this technology renaissance, research in this field is still developing. Previous research has shown that older generations have more difficulty adapting to the technology renaissance than younger generations who have been born into and raised with this technology. Several previous e-technology studies have examined the relationship of generations to this technology, especially in the field of e-learning. Many of the biological and psychological studies on the effects of aging are already in progress, but researchers should not neglect attitude surveys and qualitative studies as they explore the problem of generational gaps in e-technology. It would be of particular interest to know how attitudes toward e-technology influence the perspectives of various generations. Many studies of these attitudes and perceptions have been made in the private sector by businesses that invest in research on e-commerce. Similarly, many governments and educational researchers have advocated the improvement of education with technology and have conducted research on these attitudes and perceptions in elearning. However, e-government research is still developing because this field is the newest of the three to become widespread. Some research in e-government has focused on these attitude differences among the citizens, but no research studies have focused on the generational effects of attitude on administrators when they chose to implement etechnology. 
It is the goal of this literature review to explain the existence of generational and other demographic gaps regarding e-technology and to determine the specific issues related to these divisions. It is hoped that the issues related to demographic divisions in etechnology can be used for future research to determine how these gaps could affect other e-technology fields, such as e-government or e-commerce. The generational studies on etechnology in this paper are organized chronologically to show the development of the generational research in e-technology and the potential for expertise as a confounding variable in these studies; however, the paper begins with a brief review of generational research in general. Next, this research explores e-government, one of the most recent etechnology fields to develop, with a particular focus on the specific obstacles that have been shown by previous research to affect e-government implementation by public administrators. Finally, this paper proposes research to examine the effects of the independent variables of age, gender, location, and education with the factor of expertise on the attitudes of public administrators toward e-government.

This literature review of generational studies on e-technology examines studies and literature in the field of e-technology dealing with generational and other demographic differences over the past 24 years. Initially, sources that examined the importance of generational research and specific studies related to information and communication technology (ICT) were reviewed. Then studies that predicted the future of this generational gap in e-technology were considered to determine whether these studies included the same issues as previous studies. In addition, studies that focused solely on computer skills were not included in this review because most modern applications of e-technology involve more than basic computer skills and include ICT 
aspects such as internet use for e-mail or research. Thus, this literature review attempts to compile e-technology studies and reviews that examine a difference between the generations in order to find the issues specifically related to this difference.

\section{The Importance of Generational Research}

Researchers in the field of generational studies have demonstrated the importance of generational research for further understanding of the relationships and differences that can exist among generations of people. Generational research is important for discovering the diverse generational differences that exist and fostering an understanding of that generational diversity. Grenier (2007) elaborates on the importance of generational research by explaining that "reflecting on personal views, understandings of aging and generational memberships can help to illustrate similarities and differences and provide insight into possible intergenerational conflict" (p. 724). Generational research is growing in many fields, particularly in fields that concern technological developments in order to understand and integrate generational differences that may create barriers for the implementation of these innovations.

Researchers in the field of e-learning have begun to examine the differences that can exist between generations and the importance of these differences in the use of etechnology. Conklin and Robbins-McNeish (2007) argue that generational research is essential to e-learning research, particularly for training development. They write that "no discussion of e-learning is complete without examining how different age groups may respond to this type of training" (p. 38).

Training and development is one area in particular where generational differences seem to segregate the population, but there are many other areas such as adaptability and 
use that may also demonstrate a division between the generations. Generational research is important for establishing those areas within specific fields and situations in order to allow policy makers, program designers, and managers a chance to understand generational differences that may exist and modify their material or workplace accordingly. Perhaps an understanding of generational differences can resolve conflicts that occur from these divisions within the community. For example, training and development expert, Rossi (2007) states that "organizations need to make sure that employees of all generations are heard and feel respected. If they can do that, the gap will close" (p. 11). If this prediction is valid, then research into generational differences is necessary in the field of e-technology in order to help resolve generational problems that are arising from the growing technology "renaissance".

However, these suggestions also create the possibility for expertise as a confounding variable in studies of generational difference in e-technology performance. If training and development can remove the effects of age gaps, then expertise can change the effect of age and other demographic factors on e-technology. Unless researchers consider the possibility of expertise when they conduct generational research studies on e-technology, then their findings may be ignoring an influential factor on etechnology that could be reducing the generational gap over time.

Generational Research on E-Technology: The 1980's

As the technological "renaissance" was beginning to enter mainstream society in America, generational research on e-technology focused on the trainability and marketability of these technologies for the older generations. The major goal of these studies was to determine whether older generations were capable of developing expertise 
in e-technology and adopting e-technology innovations. These studies show the beginning of generational research in e-technology and reflect the development of etechnology at this time.

The first study to be examined in this review is a generational research marketing study that focuses on publicly accessible e-technology. Gilly and Zeithaml (1985) examine the adoption of consumer related e-technology by the elderly (defined in this study as 65 and older) as compared to younger generations. The technologies included in this study are scanner-equipped grocery stores, electronic funds transfers, automated teller machines, and custom telephone calling services. Based on previous generational research, the researchers' prediction is that the elderly would be less informed and less likely to try, use, or adopt innovate technology. The study was conducted with a questionnaire that was mailed to 2,500 randomly (from a database of automobile registrations in Texas and California) selected people, aged 64 and under as well as 2,500 people, aged 65 and over. Results of this survey show that the elderly are largely unaware of innovative technologies but are also capable of adopting those technologies. As the authors indicate, "that elderly consumers do accept change when the technology meets their needs and is effectively communicated" (p. 357). By demonstrating the effects of age on attitudes toward e-technology, this study establishes a need for generational research in e-technology that continued to develop with later studies into the feasibility of training older generations to use e-technology.

A later generational research study on e-technology, in 1987, reveals the differences in trainability that exist among the generations. The study conducted by 
Elias, Elias, and Robbins (1987) examine the varying abilities of the younger, middle-age, and older generations to acquire word-processing skills. The participants in this study were 15 paid female volunteers for each generational group: younger (18-28), middleaged (37-48), and older (55-67). The participants used a commercially available wordprocessing instructional program, and trainers evaluated the performance and satisfaction of the generational groups. Findings of this study reveal that all three generational groups were capable of acquiring the necessary e-technology skills being tested. However, it is important to note that the study also revealed that there are differences between the generations in terms of rate of learning and ability to learn the technology independently: "Our findings confirm [previous generational research in e-technology] that older subjects, even in the most congenial learning environments, require more time and more trainer assistance to become proficient at a common microcomputer tool (word processing)" (p. 347). This study, like many other generational e-technology studies at this time, reveals that all generations show the ability to acquire training, but older generations may not be as familiar with the technology and may require a longer and more personal training period to acquire e-technology skills (Garfein, Schaie, \& Willis 1988; Hartley, Hartley, \& Johnson 1984; Kerschner \& Hart 1984; and Zandri \& Chandress 1989). The fact that training is able to modify the effect of age on etechnology performance shows that increased expertise with e-technology can act as a moderator for the effects of demographic factors on e-technology.

Another generational research study in 1988 further examines the relationship of age to trainability in computer software programs by examining the effect of varying training methods. Gist, Rosen and Schwoerer (1988) studied the influence of age and 
training method on 146 volunteers that were classified as being younger (under 45 years of age) or older (45 years of age and older). The aim of this experiment is to determine what training methods (behavioral modeling or tutorial training) are most beneficial for the older generation when they are developing new e-technology skills. The authors hypothesized that the behavioral modeling would be more beneficial for the older generation than the tutorial training. After exposing the treatment groups to the different training methods, the groups were objectively evaluated and compared. The results did not show a strong relationship between the training methods and the success of the older participants, but the results did indicate that the older generation performed significantly lower than the younger generation. The authors suggest several sources of error that may have affected the results of the experiment. For instance, they suggest that "It is possible that with more time, older trainees may have reached the levels of mastery achieved by younger trainees. Follow-up studies should investigate possible increments in training performance for older workers freed from time constraints" (p. 264). This study, as well as other studies at the time, show that generational differences do not prevent the acquisition of technology skills but do affect the training.

A final study that demonstrates generational research during the 1980's is a study that examines the combined effect of age and education in an analysis of attitudes toward e-technology. Morris (1989) conducted a computer-assisted telephone-interview with randomly selected participants, and he divided the results into comparison groups based on generational status, younger (under 60 years of age) and older (60 years of age and older); educational status; household income; and gender. The findings of this survey were analyzed by a Computer Orientation Scale (COS) designed for this study and were 
also subjected to further regression analyses to determine relational effects. The results of this analysis show that there is a correlational effect between the age and education of the participants with their attitude toward e-technology. Overall, the older generation had a lower level of formal education and a more negative attitude toward e-technology than the younger generation, and Morris argues that this difference between education level and attitude is changing due to societal changes. Morris hypothesizes that in the future this difference will decrease as the "generation gap or cohort variation in educational differences declines" (p. 77). This study was replicated in 1999 (the results were not published until 2004) in order to compare the findings and see whether they have changed, and the results of that study will be discussed later in this review. Generational Research on E-Technology: The 1990's

The first half of the 1990's was not marked by much significant generational research in the field of e-technology. Most of the studies that were conducted at this time continued research from the decade before, such as studies that further examine attitude differences. Other generational research studies at this time that have contributed to the field of generational research in e-technology were based in the field of psychology ( Cerella 1990; Salthouse, Legg, Palmon, \& Mitchell 1990; Myerson, Hale, Wagstaff, Poon, \& Smith 1990; Cherry, Park, \& Donaldson 1993; and Campos \& Sueiro 1993). These studies include factors such as visual imagery ability, memory, and vision problems. However, due to the fact that these studies did not specifically integrate age as a factor for comparison in e-technology research, these studies are not being included in depth in this literature review. 
The first generational research study of the 1990's that this review examines is another study on differences in attitude between the generations in regard to e-technology. Baack, Brown, and Brown (1991) conducted a survey with 235 young adults (college students taking business and recreation classes at a large Midwestern university with a mean age of 22.4 years) and 184 older adults (members of retirement groups from churches in several small and large Midwestern cities with a mean age of 73.6 years). The survey was a 20-item Attitudes Toward Computer Usage Scale (ATCUS) that revealed a generation gap in attitudes toward various computer usage situations. The findings reveal that older adults showed a more negative attitude overall compared with the younger adults. Furthermore, older adults did not have a negative attitude toward technology in general, but they were "less eager to involve themselves with computers in a hands-on, interactional way" (p. 431). The authors note that, at this time, e-technology, such as electronic scanners in grocery stores, is being adopted by the older generations that were not previously accepting of this technology. The authors suggest that, with proper external motivation, attitudes in the older generation could become more positive regarding e-technology: "unless the benefits of acquiring such skills are readily visible, older adults will have little motivation to learn. Just as grocery store price scanners have become familiar and accepted, other computer uses beneficial to older adults can also gain acceptance" (p. 431). Thus, this study shows the importance of attitude studies in generational research on e-technology.

The next generational research study of importance for this literature was a study in 1993 involving age differences in the performance of e-technology tasks, specifically computer-based work. Czaja and Sharit (1993) conducted their experiment with 65 
female volunteers, ranging in age from 20 to 75 years, and measured the participants' ability to perform three real-world computer tasks: data entry, file modification, and inventory management. Overall, age directly affected response time and accuracy (number of errors) negatively. The authors argue, however, that experience is also a direct determinant of response time and accuracy, and the older participants also showed a lower level of experience. Thus, the authors conclude that "more studies are needed to more fully understand the role of experience in modifying the performance of older people for computer-based work" (p. 67). Thus, this author suggests expertise as a possible confounding variable in his generational research.

The middle of the 1990's contained many important literature reviews that examined the relationship of age differences to e-technology by compiling data from research up to that point (Kelley and Charness 1995; Lawhon, Ennis, and Lawhon 1996; and Hutchinson, Eastman, Tirrito 1997). For example, Kelley and Charness (1995), discusses the issues related to training older adults e-technology skills. This review focuses on many of the biological and psychological factors related to generational performance differences with learning computer technology. The review shows that specific biological, such as fatigue, and psychological differences, such as anxiety or attitude, may be responsible for the differences in learning times between the generations. Another important generational research literature review at this time was Lawhon, Ennis, and Lawhon (1996) that examines the relationship of the older generation and computers. This review argues that the older generation is capable of adapting and using etechnology with proper training; thus, the author also supports the possibility of expertise as a factor that could confound generational studies by reducing the effects of age and 
perhaps other demographic differences. The authors argue that the benefit of etechnology for the well-being of the older generation is important and requires further research into the availability of computer training for this age group. Both of these literature reviews compile previous generational research studies in order to argue for the importance of proper training being available for the older generation in order to reduce the effects of a generation gap in e-technology. The argument for proper training also supports the possibility of expertise as a confounding variable in generational research studies because the improvement of skills could reduce differences in performance.

The later 1990's saw an increase in generational research on e-technology that maintained a focus on scientific or psychologically based differences, and the next important study for this literature review is a motor control study in 1997. Walker, Philbin, and Fisk (1997) studied generational differences in motor control with the use of a computer mouse and various cursor movement tasks. The authors use a comparative study between an older and a younger group and hypothesize that the younger group will perform higher than the older group. The findings of this study confirm the hypothesis, and the younger group outperformed the older group in all areas. An interesting finding from this study was that the older adults used different strategies for movement control, and these strategies were analyzed in light of the optimized submovement model: "older adults compensated for the greater noise and less perceptual efficiency by adjusting the velocity and number of submovements" (p. 49). These results indicate that older generations may have coping mechanisms for adopting e-technology that counter naturally occurring biological or psychological issues. This study demonstrates that the 
focus on biological or psychological factors in relation to the generational divisions in etechnology was continuing in the late 1990's.

A training study a year later also showed the effect of motor control differences between the generations, but this study compared a possible generational division within the older population. Echt, Morrell, and Park (1998) studied the effect of age and training formation on the acquisition of basic computer skills by the older generations.

Participants in this study included 92 "community-dwelling" residents that were grouped as being "young-old" (aged 60-74) and "old-old" (aged 75 to 89) and were excluded if they had prior computer experience, and the training formats in the study included an online tutorial and a paper instruction manual. The authors hypothesized a higher success rate with the online tutorial due to the realistic nature of the instruction, but no difference in training method was observed. Overall, the study showed that the older generation made more motor control errors, needed more assistance, and took longer to learn the etechnology skills. The authors caution the reader on these findings because they are not supported by previous research: "These findings, however, are the first to document agerelated differences in computer task performance between different segments of the older population" (p. 15). This research shows a generational divide even within the older segment of the population, and this divide indicates a need for further generational research on e-technology that examines possible divisions between other age groups that may have been over-generalized in previous research. This closer examination of the generations and the creation of additional generational divisions is an important finding in the generational research of e-technology, and many studies in the 2000's continued this method of closer generational analysis. 
The final article that represents generational research in the 1990's on etechnology is another study that examines the relationship of age to motor control. Smith, Sharit, and Czaja (1999) examined the performance of the participants' computer mouse control skills in four basic tasks (pointing, clicking, double-clicking, and dragging). The participants were divided into three generational groups: 20-39, 40-59, and 60-75 years of age, and these groups were compared against the performance results of the study. The results of this comparison revealed that the older generations needed more assistance to accomplish the tasks. In addition, complex tasks (clicking and double clicking) were more difficult for the older generations, and the authors conclude that "age-related changes in psychomotor abilities were related to age differences in performance” (p. 395). The authors further suggest that the results of this study could be used to adapt computer mouse design to accommodate users in older generations. This study shows the evolution of generational research in e-technology during the 1990's that began with a focus on biological or psychological differences between the generations and the effects of these differences on e-technology use and concluded with marketing possibilities based on this research.

Generational Research on E-technology: 2000 to the present

Perhaps it was due to the publicity of the changing millennium or the advancement of the technology "renaissance" to this point, but whatever the reason, beginning in 2000, the amount of generational research being conducted increased greatly. A study by Lenhart (2000) that was part of the Pew Internet and American Life Project reveals that older users are less likely to use the Internet and are more resistant to the idea of adopting this technology: 
$87 \%$ of those 65 and over do not have Internet access... [, and] 74\% of those over 50 who are not online say they don't plan to get Internet access, while $65 \%$ of those under 50 say they plan to get Internet access. (p. 2) These results show the effects of a generational gap on e-technology attitudes, but it is difficult to determine whether expertise is also interacting with the factor of age in this study. Many literature reviews at this time indicate the separation of the generations and make predictions for the future development of the internet that includes a closing of the generational gap as experienced users become the older generation (Gronbach 2000; Community Banker 2000; Garrison 2000; Roberts-Witt 2000; Crowe 2001; and Government Executive 2001).

Thus, many researchers demonstrate that expertise could be a confounding variable in generational studies on e-technology. In addition, many generational research studies and literature reviews on e-technology began to be produced in locations that had not previously focused on this relationship (Crossan, Martin, \& Whittaker 2001; McDaniel 2002; and Trentin 2003). Along with attitude surveys and psychologically or biologically based generational performance studies, generational research after 2000 began to include more studies on modifications to current technology, based on the specific findings of the previous psychological and biological generational differences revealed in the field, as well as evaluations of differences in task performance between the generations that included more generations and more complex tasks than previous research, such as the search and retrieval of information or use of network structures.

The first study, for this period, continues research of the 1990's that examined more generations than the traditional generational divisions and is an experiment between 
the young-old (60-74 years of age) and the old-old (75 years of age and older) with the use of Internet technology. Morrell, Park, Mayhorn, and Kelley (2000) conducted their experiment with 30 young-old and 30 old-old community-dwelling resident volunteers and evaluated the participants' performance on bulletin board tasks. The researchers tried to eliminate the effect of previous experience by determining that none of the participants had previous bulletin board or Internet experience. Researchers hypothesized that the young-old would outperform the old-old and that the old-old would perform better with simple instructions than with expanded instructions. They also hypothesized that a measurement of cognitive ability could be used as a predictor for computer skills acquisition. The findings of the study confirmed all three hypotheses, and the researchers argue that these results indicate that simple instructions should be used with older adults in order to account for memory retention during skill acquisition: "It may be better to use simple instructions when training older adults to perform computer or similar tasks because they place less demands on cognitive abilities" (p. 233). The authors of this study suggested that the cause of the generational gap is based on biological or psychological factors, as shown by the results of the cognitive assessment.

However, Morrell, Park, Mayhorn, and Kelley (2000) had many limitations in this study that were not accounted for. First, the authors only measured the participants' experience with bulletin boards or the Internet, but any experience with computer use could enable the participant to have some advantage over a participant with no computer experience at all. Thus, expertise could be a confounding variable in this study. The authors should have performed a more extensive examination of the participants to remove the chance of interference from the factor of experience in the results. Also, the 
researchers never considered the differences in attitude in relation to the technology, and these differences in attitude may have revealed a difference in performance that is not entirely biologically or psychologically based. It is difficult to determine what factors caused the generational gap in e-task performance, but this difference is still prominent and requires further research.

Freudenthal (2001) examines the effect of generational differences in performing information retrieval tasks. The study included 32 volunteer participants: 16 younger (18 to 25 years of age) and 16 older (60 to 70 years of age), and no evaluation of previous computer experience was made. Two experiments were conducted in order to test the speed of information retrieval and working memory load of the participants. Freudenthal also had the participants complete a movement task in order to eliminate delays in response time due to difference in movement speed. However, both experiments revealed a negative effect of age as the older participants took longer to complete the information retrieval tasks (this time increased for older participants with depth of retrieval) and performed lower on the working memory load assessment. The results of this study show that program designers should bear the biological and psychological constraints of older generations in mind when creating materials: “As deep menu structures appear less suited for the older user, this suggests that designers aim to keep the number of available options low (thus avoiding the need for deep menu structures) or consider alternative means of structuring the various options" (p. 21). This experiment demonstrates the use of biologically or scientifically based generational differences to suggest advancements for the accessibility and marketability of e-technology; however, this study does not consider the expertise of the participants with e-technology, and differences in 
performance speed between the generations could be due to familiarity with computerbased information retrieval tasks rather than biological or psychological constraints. Thus, expertise could have been a confounding variable in this generational study.

The next generational research study examines the relationship of computer use to overall psychological well-being. Chen and Persson (2002) surveyed 178 younger people (17 - 30 years of age) that received college course credit for participation and 218 older people $(60-101$ years of age) that were recruited from resident communities in Ohio to compare their personal characteristics, such as reported internet usage, with their psychological well-being as determined by a survey instrument created for this study. The authors hypothesized that the younger generation would use the internet more frequently but that the older generation that did use the Internet would have a more positive psychological well-being proportionate to their amount of usage. The findings of the study revealed that all of the younger generation used the Internet, but only $18 \%$ of the older generation had used it before. Of the internet users in both generations, there was no significant difference in the amount of use per week. The results maintained the hypothesis that older adults who use the internet have a more positive psychological wellbeing, but, contrary to the hypothesis, the results did not support any relationship between the amount of Internet usage and degree of psychological well-being. The authors conclude that although the degree of well-being is not proportional to the amount of usage it is important for older generations to use computers in order for them to maintain a positive psychological well-being: "our findings that elderly Internet users reported greater levels of both purpose in life and personal growth indicates clearly that older adults could benefit from access to computers as well as computer training" (p. 742). 
However, this logic maintains that the use creates the psychological well-being, but as the authors even indicate themselves, "prior differences in psychological well-being and personal characteristics between [the participant groups] may exist”. Thus, the participants' psychological well-being (such as attitude) may not have been the result of their computer training, and, instead, this psychological state may have been the determiner for their willingness to adopt this technology.

Another generational research study at this time that analyzed more generations than previous research examined generational differences between students in seventh and eleventh grade with e-technology. Colley and Comber (2003) administered a teachersupervised questionnaire to groups of younger (144 female and 220 male, 11 - 12 years of age) and older (273 female and 302 male, 15 - 16 years of age) in order to compare computer use, experience, and attitudes with age and gender. The authors hypothesized that age differences would decrease in comparison with their earlier study due to the evolution of technological availability and instruction in primary schools but that the older generation would use more complex tasks necessary for their school environment. Findings supported this hypothesis to an extent, but a generational gap was still observed for males and females: "Age differences were present in both use and attitudes" (p. 159). Also, the results supported the initial hypothesis that the older generation would use tasks more related to their advanced school environment. This study showed the effect of a generational divide within an age group that is usually considered to be one generation. This finding is important for later generational research that indicates that the generational divide in e-technology may exist in smaller increments than traditional 
generational boundaries. In addition, the use of gender by the researchers shows the importance of other demographic factors in generational research.

In 2003, another generational research study on e-technology used previous biological and psychological research to create the basis for an experiment with the use of hypertext, a linking system within a text document. Lin (2003) conducted this experiment with 20 younger ( $20-32$ years of age) and 20 older (61 - 85 years of age) in order to determine whether differences existed between the generations in the performance of hypertext tasks in relation to the complexity of the text structure (hierarchical, network, or hybrid). Lin hypothesizes that, based on previous generational research with spatial ability; the older generation will perform worse than the younger generation proportional to the complexity of the text organization. The findings of the study support this hypothesis and demonstrate that the older generation had more difficulty with hypertext tasks, and the complexity of the text organization determined the degree to which they had difficulty. The author concludes that these findings do not mean that complex organization of text structures should be avoided with hypertext. Instead, the author suggests that proper organization of the text should be based on the situation and the intended audience. The author notes that the findings of this study are "particularly important for [texts delivered to an older audience], as they are more likely to suffer from the impact of the navigation disorientation in the use of hypertext" (p. 225). This study is important for the development of generational research in e-technology because it incorporates earlier biological and psychological generation studies with more advanced, modern e-technology use. 
In 2004, the results of a generational research study in 1999 that reconducted the study by Morris (1989) was released. DeOllos and Morris (2004) conducted their 1989 survey again in 1999 in order to see whether a decade of time had influenced the data relationships. The authors hypothesize that the prevalence of technology in society will reduce the factor of age as a difference among users over time as experienced users become the older generation. However, the findings of the second survey show no differences from the first survey results a decade earlier, and the older generation still showed an effect of age on determining attitude toward e-technology. The authors argue that although these results do not yet show a difference they hypothesize that this generational gap will close with more time:

It remains to be seen if the widespread prevalence of the computer and corresponding skills will drastically reduce, if not eliminate, the impact of age, especially on negative attitudes toward the computer, as those who are currently in their 20s and 30s enter their 60s (p. 435).

This study is important to a review of generational research in e-technology because it shows that the generation gap has not yet diminished and that age affects attitudes towards e-technology. However, perhaps the authors should focus on expertise rather than simply using age in order to determine the nature of the gap in the attitudes toward e-technology.

The next generational research study in this review demonstrates the use of more advanced e-technologies than research in the previous decades, and this study uses previous research as a basis for an experiment that aims at reducing a generation gap in performance with e-technology. Stoltz-Loike, Morrell, and Loike (2005) conducted three 
experiments with older adults (50 - 69 years of age) to establish initial performance and problem areas in using the software and two other experiments to determine whether modifications based on performance could correct initial problems that the participants had with the software (one based on NIA guidelines and the other based on the results of the first experiment). This study uses previous generational research studies in etechnology to determine that older users have more difficulty with e-technology, and this study focuses on the possibility of using situation-based evaluations and modifications to correct those problems. The authors hypothesized that the corrective procedures should improve the performance of the older adults and lessen the impact of a generation gap on performance and that the custom-designed corrective procedures provide an even higher performance. The findings of this study support the hypotheses of the authors, and the participants performed the best on the custom-designed program. The authors use these results to conclude that "this study demonstrated that people over age 50 are able to use e-learning material if it is designed to meet their specific needs" (p. 781). However, researchers should be careful in generalizing these findings to a larger population because this study was conducted with only 20 participants. Further research with a larger sample in comparison with a younger sample is necessary to make any generalizations about the effect of custom-designed programs on reducing the effects of generational gaps on etechnology performance.

Another study that focuses on reducing the generation gap in e-technology by correcting problems identified in previous research is an experiment that evaluates the possibility of changing attitudes in the older generations in order to increase usage. Melenhorst, Rogers, and Bouwhuis (2006) conducted qualitative focus groups with 48 
independently living older American (65 - 80 years of age) and 20 independently living older Dutch (65 - 80 years of age) volunteer participants. Interviewers conducted open discussions with the groups and discussed methods of communication that the participants preferred to use. Then interviewers explicitly focused the discussion on the use of e-mail. The discussions were all recorded on audiotape; professional transcribers documented the sessions; and two independent coders evaluated the data. The findings showed that participants that had experience or no experience with e-mail both viewed email as a different form of communication than traditional modes. In addition, researchers found that benefit seemed to be the main incentive that drove the use of etechnology among the older generation. The authors conclude that their research did not consider a comparison with other generations but that the attitude findings of the study support previous generational research in e-technology: "Although age groups were not compared in this study, theories [in previous generational research in e-technology] are consistent with our finding that benefit perception is decisive in older adults' choice for innovation" (p. 195). This research shows a trend in recent generational research in etechnology to use qualitative studies to find causes for the results of previous studies that showed the effect of a generational gap, and, in particular, this study focuses on the differences in attitudes toward e-technology that may exist.

Another qualitative generational research study at this time was conducted as a case study with a group of highly trained Information Technology (IT) workers. McMullin, Duerden Comeau, and Jovic (2007) review previous generational research as well as a case study of IT workers to discover generational differences and similarities with regard to e-technology. Initially, the researchers review past research and conclude 
that generational boundaries should be based on differences in the available technologies of the era: Pre-Atari (born before 1955), Atari (1955 - 1963), Console (1964 - 1973), Windows (1974 - 1978), and Internet (1979 - present). The researchers then analyzed the results of semi-structured interviews with 141 IT workers (with an average age of 37 years) from small firms (employing 4 - 21 workers) in terms of these generational boundaries. The researchers hoped to identify factors within the generational groups that connected the members to a community of discourse that separated them from the other generational groups. The researchers found that there are common affinities shared by members of the generational groups and that these affinities can isolate the discourse communities of those generations: "Respondents prioritized generation over other bases of difference. Hence, the articulation of affinities and inequalities through generation is significant" (p. 314). The authors even suggest that these boundaries may influence the relationship of generational differences to e-technology in other fields besides IT: "Whether and how generational affinities to computing technology shape work environments and concepts of skill in other industries remains to be seen" (p. 314). This suggestion for future research is interesting because it proposes that the discourse community created by generational gaps may affect judgments and attitudes to etechnology in other fields, such as e-commerce or e-government.

\section{The Case of E-Government}

According to many experts and surveys, the use of electronic technology to facilitate services from the government to the citizenry is on the rise (Moulder, 2001; Evans-Cowley, J. \& Marita Conroy, M. 2006; CMA Management 2001; Ya Ni \& Bretschneider 2007; Ho 2002). The fact that this technology is a modern innovation and 
has not been fully studied, however, creates potential problems for administrators who are trying to evolve with the technology and create electronic government (egovernment). E-government does not even have a precise definition but is instead a loosely defined theory of governance that can include many things from specific actions that allow a citizen to communicate with the government over the internet to virtual networks that link city and state governments. The primary focus of e-government theory is to increase the efficiency and effectiveness of government through the use of technology, but the relationship between bureaucracy and technology is not always complementary. The nature of bureaucracy is to preserve stability, and the nature of technology is to innovate and provide modern solutions to situations. Administrators decide the terms and implementation of this relationship between bureaucracy and technology. Several previous studies have examined the potential problems that can occur for administrators as they introduce technology to government, but due to the recent innovation of e-government, these studies are still developing.

The goal of the e-government section of this literature review is to examine and compile e-government studies in order to find the potential problems that public administrators can face as they combine technology and bureaucracy. This review hopes to add to the previous research by combining those various problem factors from the previous studies into major areas of concern that can be studied later. This review suggests that further studies should be conducted with public administrators to determine how these key obstacles effect the introduction of e-government. In order to provide a background for the specific problems demonstrated in the previous studies, this review 
E-government Attitudes 35

begins with an analysis of the relationship that is developing between bureaucracy and technology.

\section{The Relationship of Bureaucracy and Technology}

Government reform has been an important subject for both academic and practical discussions in the past two decades (Moe, 1995.; Osborne \& Gaebler, 1992; Peters, 2001; Peters \& Pierre, 1998; Pierre, 1995; Thomas, 1998; Brescia \& Daily 2007). Bureaucracy has traditionally been paper based and often hierarchical in structure. The past two decades, however, have seen a revolution in bureaucracy with the rise of technology. According to Riley (1997), "The transition from the Paper Age to the Digital Age has brought with it new issues for the collection, management and dissemination of information" (p. 1). These issues have still not been resolved, and the coordination of bureaucracy with technology remains a difficult relationship that administrators are struggling to manage. Geffen (2006) notes that "department heads and program leaders must be clear that holistic and multi-departmental solutions are now possible and demand their design and implementation" (p. 17). The reorganization of bureaucracy is a difficult task due to the fact that the nature of bureaucracy has traditionally preserved stability.

The nature of technology, however, creates innovations rather than preserves stability. Bill Gates, the founder of Microsoft, (2008) writes of the technology revolution that "technology is transforming how we interact with each other and understand the world we live in. To a great extent, this process is just beginning" (p. 74). The fact that technology functions as an agent of change and bureaucracy functions to preserve stability makes the integration of the two into e-Government a difficult process. In addition, to the innovations provided by technology are constantly improving makes it 
difficult for administrators to determine the extent to which the bureaucracy should be affected by this revolution. For example, passports are now being equipped with RFID (radio frequency identification) technology to prevent fraud, but the new LSA (laser identification) technology can uniquely identify a single piece of paper and replaces the previous RFID technology in terms of cost and equipment by storing a database of paper "fingerprints" instead of equipping each passport with a radio frequency device. In order to moderate the relationship between technology and bureaucracy, there are several key obstacles that public administrators should consider as they introduce technology to government. This literature reviews those obstacles as identified by previous research in e-Government.

\section{Lack of Standardization in Previous E-Government Studies}

One of the challenges for public administrators is the lack of standardization in previous e-Government research. Due to the fact that the technology revolution is a fairly recent innovation that is still developing, the important areas of concern for public administrators have not been conclusively determined. Instead, many researchers have chosen to select their own specific areas of concern for e-Government that may not be sufficient. This literature reviews examines e-Government books, articles, and government reports from the past two decades in order to compile those various concerns into broad areas of concern for public administrators.

This literature review focuses on sources that examine the relationship of technology and bureaucracy, and in particular, this review focuses on the potential problems that can occur for public administrators managing this relationship. Sources that focus on business or ethics were not included in this review. Business sources were 
excluded due to the fact that the nature of business to create a profit is in contrast to the nature of bureaucracy to provide the most efficient and effective services to the citizenry. Carter and Belanger (2005) state that

Businesses are allowed to choose their customers; however, in egovernment, agencies are responsible for providing access to the entire eligible population, including individuals with lower incomes and disabilities. The digital divide makes this task of providing universally accessible online government services challenging. (p. 7)

Ethics sources were excluded due to the fact that ethical values are different in various locations, and this concern is relative to the location of the administration. Instead of focusing on these differing factors, this review focuses on the specific problems that occur for public administrators in a general government setting.

\section{The Obstacle of Public Access}

The first area of concern for public administrators introducing technology to government is public access. Many previous studies have focused on the problem of public access to e-Government (Von Haldenwang 2004; PA Times 2003; PA Times 2007; Carter \& Belanger 2005; Jain, Mandviwalla, \& Banker 2007; Qureshi 2005; Jaeger 2004; Bacher 2002; Norris \& Moon 2005). Public access includes not only the availability of information but also measures to bridge the digital divide.

The extent to which information should be available to the public can be difficult to determine, but some experts argue that in order to develop fully integrated egovernment the citizens have to be able to access information at all levels of the egovernment system, including not only traditionally available information but also 
information about the decision making processes of the administration. For example, Bovens and Zouridis (2002) state that "Citizens and interest organizations should be able to access the electronic forms, decision trees, and checklists used by the organization to make decisions directly on the Internet" (p. 183). Some public administrators, however, feel that this availability of information would compromise security, and this concern about security will be examined later in this review.

The other concerns about public access focus on problems related to the digital divide that exists between citizens and the administration and among administrations themselves. According to Wilhelm, Carmen, and Reynolds (2002), "In the mid-1990s the phrase "digital divide" - the inequality that exists between individuals who have access to information technology (IT) and those who do not - became part of our country's vocabulary (p. 2). The development of e-Government has continued to focus on this obstacle of a digital divide that exists due to poverty, disability, language, or other factors that inhibit the introduction of technology to government. Brescia and Daily (2007) describe the digital divide as it concerns access problems related to poverty and lack of technological ability:

As literacy in and access to information technology is quickly becoming essential to participation in the new technology-based economy, the existence of an informational divide that reflects the socioeconomic situation of users and nonusers or the "information rich" versus the “information poor" is a growing concern. (p. 23) 
In order to provide proper public access to government through technology, administrators have to solve this digital divide and integrate citizens who may not be prepared or capable otherwise.

Disability has become an important factor in the obstacle of public access. Despite governmental policy objectives, such as the amended Section 508 of the Rehabilitation Act of 1973 by the Congress, the issue of public access for people with disabilities is still a major concern. Section 508 was designed to remove obstacles to information retrieval by disabled people by requiring federal agencies to make their information technology (IT) accessible for all people, even those with disabilities. However, Sobie (2003) concludes his analysis of e-government access for persons with disabilities by stating that the problem of access for the disabled is growing: Increased accessibility, by persons with disabilities, to information and services delivered to citizens through government web portals, may not be keeping pace with the proliferation of e-government initiatives. The digital divide may in fact be expanding for persons with disabilities rather than closing. (p. 7)

In a review of the previous literature concerning disability and technology along with an analysis of the 2003 census data, Dobransky and Eszter (2006) conclude that the "findings [of the study] suggest the need for public policy that encourages access to assistive technologies that are more affordable and more up-to-date to help bridge the divide between people with and without disabilities" (p. 330). This issue of disability is a part of the obstacle of public access, which administrators should consider when they introduce technology to government. 
This digital divide is especially pronounced in developing countries where citizens often lack access or ability to use many modern technologies, including the internet. Crenshaw and Robison (2006) state that one "of great concern [for eGovernment] is the 'digital divide' between rich and poor nations" (p. 190). Crenshaw and Robison measure this digital divide by the amount of technology distributed throughout the population on an individual basis. Many experts have followed this same method for examining the digital divide and rely on census reports to determine the disparity that exists between the technologically rich and poor. James (2005), however, disagrees with the traditional method of evaluating the digital divide with individual ownership by stating that "while this measure makes sense in the rich countries, where individual ownership is widespread among the population, it makes very little sense in poor countries" (p. 114). James argues that poor communities may have some level of access through communally shared technologies. Whether the digital divide is based on poverty, disability, or some other limitation or is measured individually or communally, the disparity remains, and this issue of public access seems to be a major obstacle for the implementation of e-Government in many communities around the world.

\section{The Obstacle of Limited Resources}

Several of the articles concerning e-Government discussed the issues of limited financial, human, and technological resources as barriers to the introduction of technology to government (Moon 2002; Moulder 2001; General Accounting Office 2007; Ho 2002; Rogers 2003). For the purposes of this literature review all of those limitations were grouped under the topic of limited resources. These limited resources were often indicated as the most important barrier to the introduction of e-Government. For example, 
Moulder's (2001) International City/County Management Association (ICMA) survey showed that the lack of financial resources was the most important barrier to eGovernment and that the second most important barrier was the lack of technological or human resources. In addition, the General Accounting Office (2007) of the United States of America declared that "implementing effective funding strategies" was in the top five key challenges to the introduction of e-Government (p. 43). An analysis of the literature concerning the budget obstacle to e-Government reveals that there are two main issues concerning budget problems: the lack of funds to afford the initial cost of technology and the rising cost of e-Government implementation.

The budget limitation that prevents the introduction of technology to government is an important factor in e-Government adoption, both in local governments and globally. Local governments do not share a standard budget with one another, and some local governments may be unable to fund e-Government developments that other governments are able to adopt. For example, Jain, Mandviwalla, and Banker (2007) describe the Municipal Wireless Network (MWN) that Philadelphia, Pennsylvania has adopted and the difficulty in establishing such a governmentally controlled technology initiative: "Because of renewed faith in market-based mechanisms, the failure of some governmentoriginated initiatives, and the burden of substantial government fiscal debt[, it] is increasingly difficult for governments to play the role of a catalyst in achieving technological and social objectives" (p. 1004). Other cities do not even have the ability to risk adopting a technology system like a MWN because their finances are too limited to afford the initial expense. 
Experts have also argued that the implementation is particularly difficult in countries with very limited budgets (Kenny 2002). As the Economist (2001) indicates, "Politicians in poor countries all want their countries to become more technologically competent [, but $]$... it is hard for governments to pick winners in technology" (p. 12). It is difficult for these poor governments because they may not be able to rely on domestic technology and are concerned about becoming dependent on outside sources for technology. Some experts advocate open-source software that is not controlled by any specific company in order to allow technological development without financial attachments. However, this technology is limited in its availability and creates a major concern for administrators due to its lack of available technical support. Also, technology has been developing at such a rapid pace that countries with limited budgets are not sure which technologies to invest in or how to update the technologies that they have already purchased due to a lack of finances.

There is a rising cost of e-Government technology that can become an obstacle to an administration's budget. Ho (2002) identifies budget limitations as an obstacle to eGovernment: "that may have prevented some cities from making progressive changes in Web design" (p. 440). For instance, in the United Kingdom, Rogers (2003) reports that "the cost of e-government to local authorities could be $£ 1$ bn more than originally anticipated, analyst firm Kable has warned." This type of increase in cost occurs not only because of advances in technological development but also because licensing, installation, maintenance, and repair create costs that may not have been included in the initial estimate of the cost of the technology. Rogers (2003) quotes Karen Swinden, the head of forecasting at Kable, in her analysis of the increase in e-Government costs in the U.K. as 
saying that "[this example] shows that e-government is more complicated and involved than councils could have imagined - it will consume a lot more of their time, energy and resources."

\section{The Obstacle of Security}

Another obstacle to the implementation of e-Government that was identified through a review of the literature is the issue of security. For the purpose of this review to identify key obstacles to e-Government, issues of privacy and security are combined because they both relate to the protection of information or the system itself. Many experts have examined the obstacle of security for public administrators introducing technology to government (Holden and Millet 2005; Dutton, Guerra, Zizzo, \& Peltu 2005; Schwartz 2005; Slack and Rowley 2004; Posner 2007; Prince 2007; Wilshusen 2007; Koontz 2007). Issues of privacy as they concern the privacy of individuals from the government are not considered in this review because these issues are not as important for the purpose of eliciting the key challenges faced by administrators as they introduce technology to government because most of these issues are decided as policies or laws rather than by administrators themselves. According to some experts, security issues are the main obstacle for e-government implementation because they concern trust in the administration. For example, Baker and Roach (2007) report that "Security tops Internet concerns. Lack of security erodes the trust needed to maximize the Internet's potential. This is especially true for e-government where interaction depends on citizen trust" (p. 7).

Recent developments in e-government have shown that security needs to become an important concern for administrators introducing technology to government. For example, the United States Department of Homeland Security (DHS) has recently 
identified several vulnerabilities in their systems. Strohm (2007) reports about this situation:

In written testimony submitted in advance of the hearing, the [Government Accountability Office (GAO)] officials say that significant weaknesses in controls threaten the confidentiality and integrity of key information systems. As a result, increased risk exists that unauthorized individuals could read, delete or change sensitive and personally identifiable information, or disrupt service on Homeland Security systems, the officials add. (p. 2)

The DHS is an administration whose focus is security, and even this administration has felt the obstacle of security as e-government was implemented. Furthermore, Gregory C. Wilshusen, the Director of Information Security Issues for the Government Accountability Office, (2007) has been quoted in sworn testimony as saying that "In their fiscal year 2006 financial statement audit reports, 21 of 24 major agencies cited information security control weaknesses. An underlying cause for these weaknesses is that agencies have not fully implemented agency-wide information security programs". The fact that almost all of the major agencies indicated that security was a key obstacle to egovernment along with the fact that there is no agency-wide information security program in existence yet emphasizes the importance of security as a major concern for administrators introducing technology to government.

The concern for security is not only important for the security issues that are specific to the administration but also for the protection of citizen trust in the program. If 
the citizens do not trust the security of the e-government program, then they will be reluctant to use this service. According to a recent survey by Hart-Teeter (2003), American citizens do not yet trust e-government fully: “a 54\% majority [of those Americans polled in the survey] think that government should proceed slowly in relying on the Internet for communication between citizens and government. A 35\% minority of senior government employees believes the government should move slowly" (p. 2). This difference in opinion emphasizes the importance of security as an obstacle to egovernment incorporation because the administration should maintain the trust of the citizens in order for them to utilize the technology. Richards (2006) reports on the importance of trust for the implementation of e-government:

A lack of trust is hampering take-up of online government services, according to a recent [British Computer Society (BCS)] Thought Leadership Debate....

Transactions where government agencies handle personal data require a greater 1 evel of trust, the debate heard. In e-service transactions, the government has to be able to demonstrate confidentiality, competence and integrity in handling a person's data. (p. 52)

Due to the fact that a lack of security threatens not only the information and system of the administration and citizenry but also the participation of the citizens in e-government, this issue is a major obstacle for administrators introducing technology to government.

\section{The Obstacle of Assessment}

Proper assessment is the final obstacle for administrators implementing egovernment in this review. Hughes (2003) describes the difficulty of assessment for e-government by stating that "Contracting out government services and 
increased tracking of individuals require sophisticated accounting and monitoring systems - all of which rely on good information technologies" (p. 201).

Administrators must consider the methods and technologies required to assess egovernment, or the implementation of e-government may decrease efficiency and effectiveness rather than promote these qualities. The proper assessment of egovernment is a difficult issue for administrators for primarily two reasons: the lack of standardized methods to measure success for e-government and the lack of time to properly evaluate the durability of e-government. Many experts discuss this problem of assessment, and as of yet there is no standardized model for assessing the success of e-government.

The first problem with assessment occurs because of the lack of standardized measurements of e-government. Several articles reveal that the use of various measurements for e-government prevents an actual evaluation of the system (Kunstelj \& Vintar 2004; Janssen, Rotthier, \& Snijkers 2004; and Lee 2006) indicate in their review of e-government assessment studies that the variety of methods for measuring egovernment creates problems for reliability:

The evaluation of eGovernment has become a booming business, as testified by the numerous benchmarking studies offered by commercial organizations (often consultants), international organizations and national governments. The different motives and targets of these studies result in different approaches to performance measurement.

There is no simple solution for combining all of these various methods of measurement, and due to the lack of a standard measurement, assessment will remain an important 
obstacle for administrators. Millard et. al. (2004) indicate that the lack of a standard measurement is due to the fact that measuring is a learning process that has no end (p. 2). This approach to a lack of standardized assessment puts the burden on administrators to decide the best method for evaluating e-government from among all of the possible measurement criteria that exist.

In addition, the recent development of e-government has prevented researchers from having enough time to fully evaluate the situation. Many experts argue that premature assessments of e-government do not actually provide an understanding of the success of the entire process (West 2004; Tolber \& Mossberger 2006 ). For example, West (2004) cautions e-government researchers: "Obviously, given the early stage of egovernment, researchers should not rush to judge e-government's ability to transform public-sector service performance, democratic responsiveness, or citizen trust in government over the long-term" (p. 24). In addition, some researchers even warn that the current use of surveys may not elicit the important information for truly evaluating egovernment. For example, Tolbert and Mossberger (2006) state that "There are also some limitations of current survey research for understanding what the potential of egovernment might be in building better relationships with citizens" (p. 366). These limitations to survey research have not yet been established because the evaluation of egovernment success is highly situational and can be difficult to measure. The reason that e-government is difficult to measure is due to the fact that researchers have not yet established which factors determine e-government success; however, with time, theorists may develop a means by which administrators can reliably evaluate their specific egovernment situation. Thus, until research about e-government has had enough time to 
develop a reliable method for assessment, the proper assessment of e-government services will remain a key obstacle for public administrators.

E-government Attitude Survey

One of the most important e-government articles for the purposes of this literature review is a study that examined the attitudes of bureaucrats and citizens regarding egovernment. Moon and Welch (2005) conducted an attitude survey with 961 citizens and 550 bureaucrats in order to determine and compare their attitudes to e-government. This study found that bureaucrats were overall more positive and informed in their attitudes about e-government than citizens. The importance of this study for the purpose of this literature review is the survey that was used to elicit the attitudes of the bureaucrats and citizens. This e-government attitude survey has been adopted by this current study, except that the citizen portion of the study has been removed, and the current study focuses on the differences within the bureaucrat population based on their demographic information (age, gender, location and education) and expertise with e-technology. The previous study also focused on attitudes toward the key obstacles to the introduction of egovernment, such as security or limited resources, rather than specific elements of egovernment, such as government websites or online voting. This survey was shown to have a high reliability in its pilot study, and the adoption of this survey is intended to build upon previous e-government research on the attitudes of public administrators. The authors suggest that future research on e-government should continue to examine the attitudes of administrators: "Future studies should continue to examine how citizens and bureaucrats change or maintain their attitude toward e-government and see whether their views become divergent or convergent" (p. 261). This suggestion is important for 
understanding the evolution of these attitude differences over time, but it is the opinion of this study that the attitude differences within the population of public administrators. Exploring these differences in the discourse community of public administrators could not only help to resolve conflicts that could be the result of demographic characteristics or expertise but also provide a starting point for comparing future research on administrator attitudes to e-government to determine whether these attitudes are also changing over time.

\section{Conclusion and Recommendations for Future Research}

This chronological review of the literature demonstrated the evolution of generational research in the rapidly developing field of e-technology. This review showed that since the beginning of the technology "renaissance", there have been divisions in performance between the generations. These gaps remain to this day, and researchers are still developing methods of assessing and minimizing the effects of this segregation. Researchers have used many different methods of explaining the gaps between the generations such as psychological or biological studies on the effects of aging, surveys of attitude and perception of technology, and qualitative research methods such as interviews and case studies.

All of these methods have demonstrated that generational gaps exist in etechnology performance, but not only have these studies not conclusively determined the cause of those gaps, they have also revealed confounding variables, such as expertise, in other studies in the field because not all of the researchers focused on the same types of causes. While some researchers base their studies on biological or psychological literature in the field, these studies often did not measure or even consider the effects of 
attitude on the study results. Other researchers have shown that attitude was related to the generational gap in performance, but often these researchers did not factor in the biological or psychological effects of aging that other studies have shown to create differences in performance. Thus, although there have been many studies in the field of etechnology that have revealed generational gaps in performance, there has been no conclusive explanation for these divisions.

As indicated in this review of the literature, researchers need to remember that expertise could function as a confounding factor in these generational research studies on e-technology. Many authors suggested that the improvement of computer skills through training and development could reduce the generational gaps in e-technology performance. These recommendations supported the fact that expertise could moderate the effect that age had on e-technology attitudes and performance. For these reasons, it was the recommendation of this review that expertise should also be considered as a possible factor of influence in generational studies on e-technology attitudes and performance.

During the past twenty years, the e-government movement has developed to introduce technology into government and provide citizens with access and information directly from their government. However, due to the recent innovation of this technology revolution, administrations are having some problems integrating the technology into government. The four main problem areas that were revealed through a review of egovernment literature are public access, limited resources, security, and assessment. Each of these areas creates problems for administrators that do not yet have solutions. For the purposes of this study, these four main barrier issues were used for the attitude survey in 
order to find differences in administrator attitudes regarding the specific issues concerning e-government according to the literature. The attitude survey being used in this study was based on a previous attitude survey (Moon and Welch 2005), and these four obstacles were substituted for the obstacle issues that were used in the previous attitude survey because they were derived from a comprehensive review of the main issues in e-government implementation rather than the construction of the previous researchers for their attitude survey. Also, due to the evolving nature of this technology revolution, administrators may not be able to rely on any specific methods or models because these methods or models may quickly become obsolete and have not yet had time to fully develop, so it was important to know how generational or expertise differences could affect an administrator's attitudes toward these four main issues in egovernment at this time.

This literature review recommended that further research be done on these four key obstacles to e-government. In particular, it was interesting to know how administrators perceive these key obstacles and if differences in opinion existed among them. For example, if there was a difference in age and the perception of technology, then perhaps administrators of different ages would evaluate these obstacles differently based on their perspective of technology. Also, research should be done on each of the areas itself to determine what components actually comprise the specific difficulties in these areas. There are no specific recommendations for applications of these key areas because they were based on an analysis of e-government literature that is still being developed. However, with further research into these obstacles, perhaps administrators can have a framework for evaluating and introducing technology to the government. This study 
provided future research based on the e-government attitude survey used by Moon and Welch (2005) to examine the main effects of demographic characteristics (age, gender, location, and education) as well as the moderating factor of expertise and the interaction effects of the moderating factor of expertise with the demographic characteristics (age, gender, location, and education) on the attitudes of public administrators to e-government. 


\section{Chapter 3: Methodology}

\section{Introduction}

This study had three main goals: to determine the effects of demographic characteristics and the factor of expertise on general attitudes to e-government, to determine the effects of expertise on participants' evaluations of the main obstacles identified in the review of literature, and to allow participants to also provide written suggestions about the obstacles to e-government. A review of the literature on generational research of e-technology revealed that demographic characteristics (age, gender, location, and education) and expertise could both affect attitudes and performance with e-technology. For this study, the demographic characteristics and expertise were used as the factors in interacting factorial designs with the dependent variable of attitudes toward e-government. The dependent variable was operationalized as an E-Government Attitude Survey that is included in Appendix B.

This survey contained a scale for evaluating e-government attitudes that was based on the surveys by Moon (2002) and Moon and Welch (2005) as well as the literature review contained in this study. Moon (2002) identified the technologies that are specific to egovernment and were used to establish the factor of expertise in this study. Moon and Welch (2005) provided the general format for the current e-government attitude survey. The literature review in this study identified four main obstacle factors to e-government: security, limited resources, public access, and proper assessment. These factors with the addition of training have replaced the obstacle factors in the previous e-government attitude study from 2005. This study followed a method of generational research of e- 
technology that has been important for exploring this developing field: an e-government attitude survey.

\section{Population/Sample}

The International City/County Management Association (ICMA) is an organization of municipal and county administrators around the world. According to the ICMA website (http://icma.org; 2008), the ICMA has a population of over 8,200 city and county administrators as members. The organization also allows students to join for more information about public administration and gives them access to the mailing lists of the members. The ICMA is a major associate of public administrators in both city and county levels of government. These administrators were chosen randomly from both city and county governments in order to have a variety of public administrators that could better represent the overall effect of age and expertise for public administrators in general. These participants were obtained from a mailing list of ICMA members. Only surveys that were returned on time and fully completed were considered for data analysis.

Of those 8,200 members, 660 randomly selected people were sent surveys by mail. Out of the 660 distributed surveys, 184 valid surveys were received which was about $28 \%$ of the total surveys (see Table 1 ).

Table 1 Sample size

\begin{tabular}{|c|c|c|c|}
\hline $\begin{array}{c}\text { Total Population of } \\
\text { ICMA (N) }\end{array}$ & $\begin{array}{c}\text { Total Number of } \\
\text { Distributed } \\
\text { Surveys }\end{array}$ & $\begin{array}{c}\text { Total Number of } \\
\text { Valid Surveys } \\
\text { Received }\end{array}$ & $\begin{array}{c}\text { Sample Size } \\
\text { (n) }\end{array}$ \\
\hline 8,200 & 660 & 184 & $184(28 \%)$ \\
\hline
\end{tabular}

The demographics for this sample size varied greatly which can be seen in Table

2. Figure 1 also shows the frequencies of each demographic group. Participants over the 
age of 50 made up the majority with 114 participants. Gender was also unequal with 50 females and 134 males taking part in the study. Location consisted of 55 city administrators and 129 county administrators. Education included 10 with some college, 51 with a college degree, and 123 with a graduate degree.

Table 2 Sample Demographics

\begin{tabular}{|lc|lc|lc|l|l|}
\hline \multicolumn{2}{|c|}{ Age } & \multicolumn{2}{c|}{ Gender } & \multicolumn{2}{c|}{ Location } & \multicolumn{2}{c|}{ Education } \\
Over 50 & 114 & Female & 50 & City & 55 & $\begin{array}{l}\text { Some College } \\
\text { College Degree }\end{array}$ & 10 \\
Graduate Degree & 123 \\
50 \& younger & 70 & Male & 134 & County & 129 & & \\
\hline
\end{tabular}

Figure 1 Demographic Frequencies

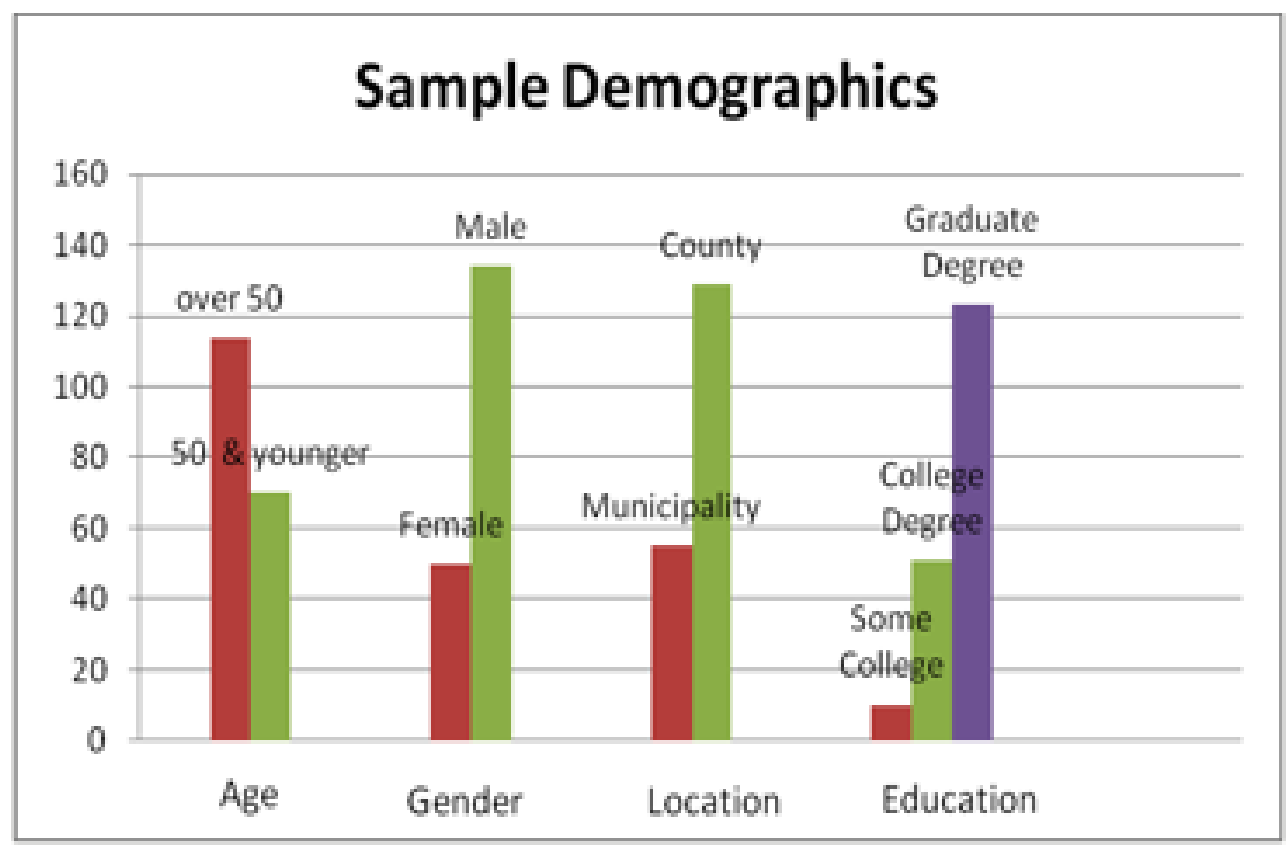

\section{Procedure/Instrumentation}

A survey questionnaire was mailed to the participants selected from the ICMA mailing list. Initially a pilot study of 10 randomly selected city/county administrators was selected from the ICMA mailing list, and this pilot study was used to provide reliability 
and validity for the main study. This pilot study is described in further detail later in this section. As stated earlier, the main study was then conducted with a sample of 660 randomly selected city/county administrators from the ICMA. This survey questionnaire was adopted from the studies conducted by Moon (2002) and Moon and Welch (2005) with slight modifications for the purposes of this study.

The survey instrument was divided into two sections according to the two types of statistics used in this survey. It elicited the descriptive statistics used in this study (age, gender, location, education, and expertise) and also the inferential statistics (the attitudes of the public administrators to e-government). The attitude section of the survey was divided into two sub-sections (general attitudes to e-government and attitudes to specific obstacles to e-government).

Like the Moon and Welch (2005) study, this study focused on the attitudes regarding the key issues to e-government rather than the specific elements. For example, the previous study asked for the participants' views on the key obstacles to e-government and listed several potential issues. This question focused on the key issues of egovernment rather than the specific elements. Likewise, the previous survey did not ask the participants' views on specific elements of e-government such as the use of government websites or online voting. This study, like the previous study, focused only on the attitudes regarding the key issues of e-government, and attitudes toward specific elements of e-government were not included.

This study examined attitude differences among public administrators and did not include the citizen portion of the previous e-government attitude survey. Other modifications to the original survey included a modification of the scale used for analysis 
to compare the factorial effects of age and expertise. In addition, the Likert-like scale in the attitude part of the survey was modified in some areas so that all of the questions included a four-point Likert-like scale. Another modification to the questions regarding the key obstacles to e-government was that these obstacles were modified in accordance with the key obstacles compiled from the review of previous e-government research rather than the same obstacles that were used in the original survey: the current study focused on the obstacles of security, public access, limited resources, proper assessment, and training. The purpose for the modification of the key obstacles was due to the lack of standardization in the research on e-government and was an attempt to focus on the obstacles that were shown in many studies to be the key obstacles as indicated by public administrators themselves.

After approved of the study by the West Virginia University Institutional Review Board for the Protection of Human Subjects (IRB), the survey questionnaire was mailed to the participants chosen from the mailing list with a cover letter (see Appendix A) that explained the study and requested their participation. These survey packages also included a return letter with prepaid postage for the participants to return the completed surveys.

\section{Pilot Study}

Due to the fact that this study did not simply adopt the previous surveys used by Moon (2002) and Moon and Welch (2005) but created a new scale for E-Government Attitudes that was based on this study's review of the literature and re-designed for the purposes of this study to examine only administrators' attitudes (as compared to administrators' and citizens' attitudes), this study required a pilot study to validate the 
scale being used. The pilot study was intended to not only provide validity but also reliability for this study. Through a comparative analysis of the results of both studies the researcher was able to determine the relative validity and reliability of the instrument. In addition, the pilot study allowed the researcher a chance to conduct the survey experiment before the actual main survey was distributed in order to observe any problems that could be encountered during the main study. The pilot study was conducted with 10 public administrators randomly selected from the ICMA. The mailing lists for the pilot study and the main study were screened to ensure that no administrators were chosen for both studies. Of the 10 surveys sent to ICMA members, four were returned which were valid for use. No major problems were found with the returned surveys; therefore, corrections with the survey were not needed for the main study. Statistics

A variety of methods were used in the statistics part of this study. These methods included t-tests, one-way factorial ANOVAs, and two-way factorial ANOVAs. The dependent variable, attitude, is a continuous variable calculated by averaging the scores on four survey items related to attitudes toward E-government. Each of the four items elicited Likert-type responses from one to four. The independent variable of age was operationalized in two groups (Over 50 and 50 and younger). The independent variable of gender was operationalized in two nominal choices (female and male). The independent variable of location was operationalized in two nominal choices (city and county). The independent variable of education was operationalized in three nominal choices (Some College, College Degree, and Graduate Degree). The moderating factor of expertise was obtained by a self-described choice provided by the participants as to their abilities with 
e-technologies specific to e-government as defined by Moon (2002) that included three choices (Beginner, Intermediate, and Advanced). It was necessary to first examine the main effects of expertise and each demographic characteristic separately on attitude to determine if a significant difference existed. For this, two different methods were used which included three t-tests with the variables, age, gender, and location on attitude and 2 one-way factorial ANOVAs were used for the variables of expertise and education on attitude. A Scheffe post hoc test was conducted if the one-way ANOVAs proved to be significant. To determine the interactional effect of the demographic characteristics and expertise on attitude, 4 two-way factorial ANOVAs were used to examine the results of the E-Government Attitude Survey. Any differences observed by the 4 two-way factorial ANOVAs were further examined with Scheffe's post hoc analysis to determine the exact location of the difference. To determine the effects of expertise on the obstacles to egovernment, 5 one-way factorial ANOVAs were used and if any significant differences existed, a Scheffe post hoc test was performed to find where the differences occurred. 
Figure 2 Independent Variables on the Dependent Variable (Attitude)

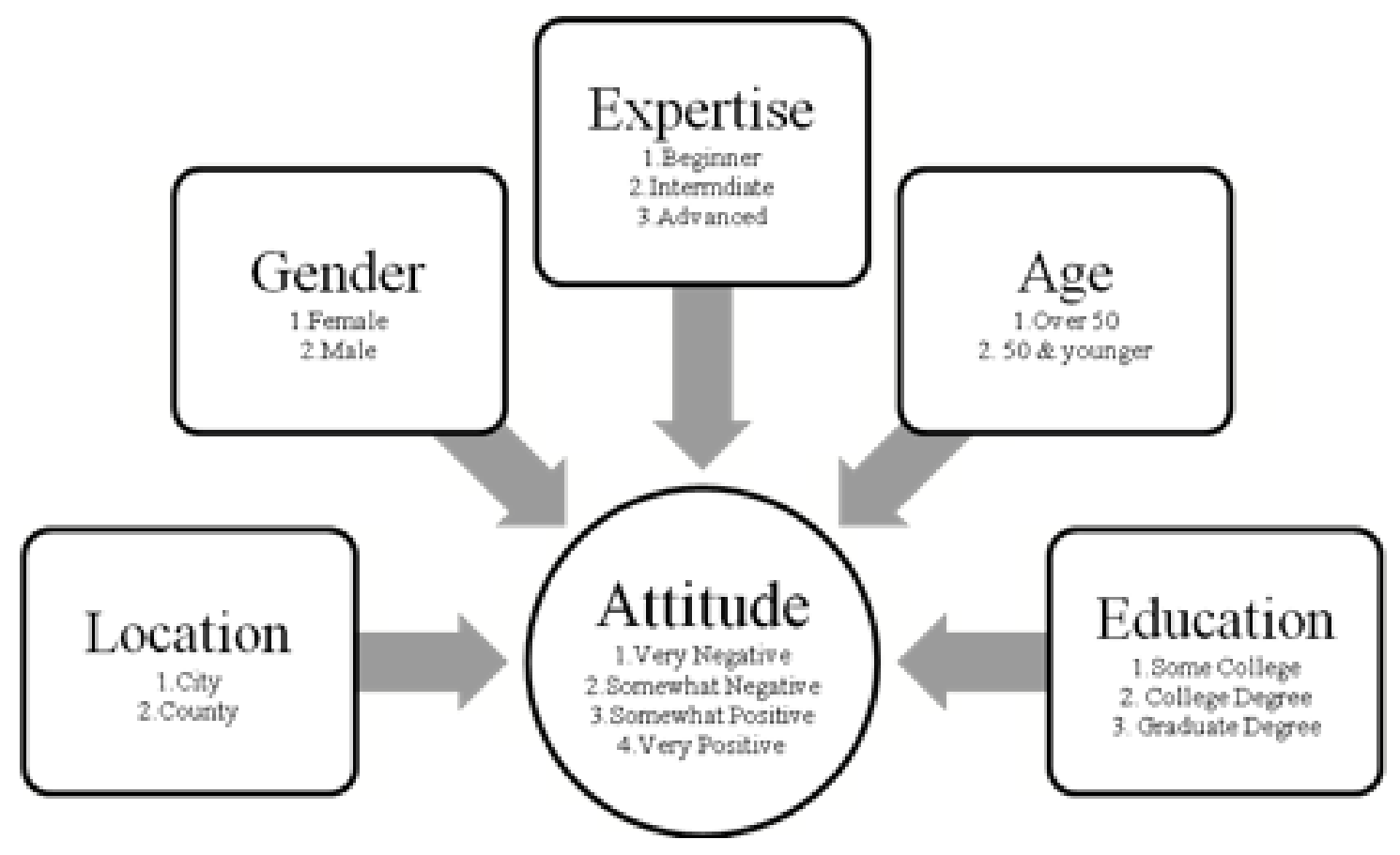


Figure 3 Interactions of Independent Variables on Dependent Variable (Attitude).
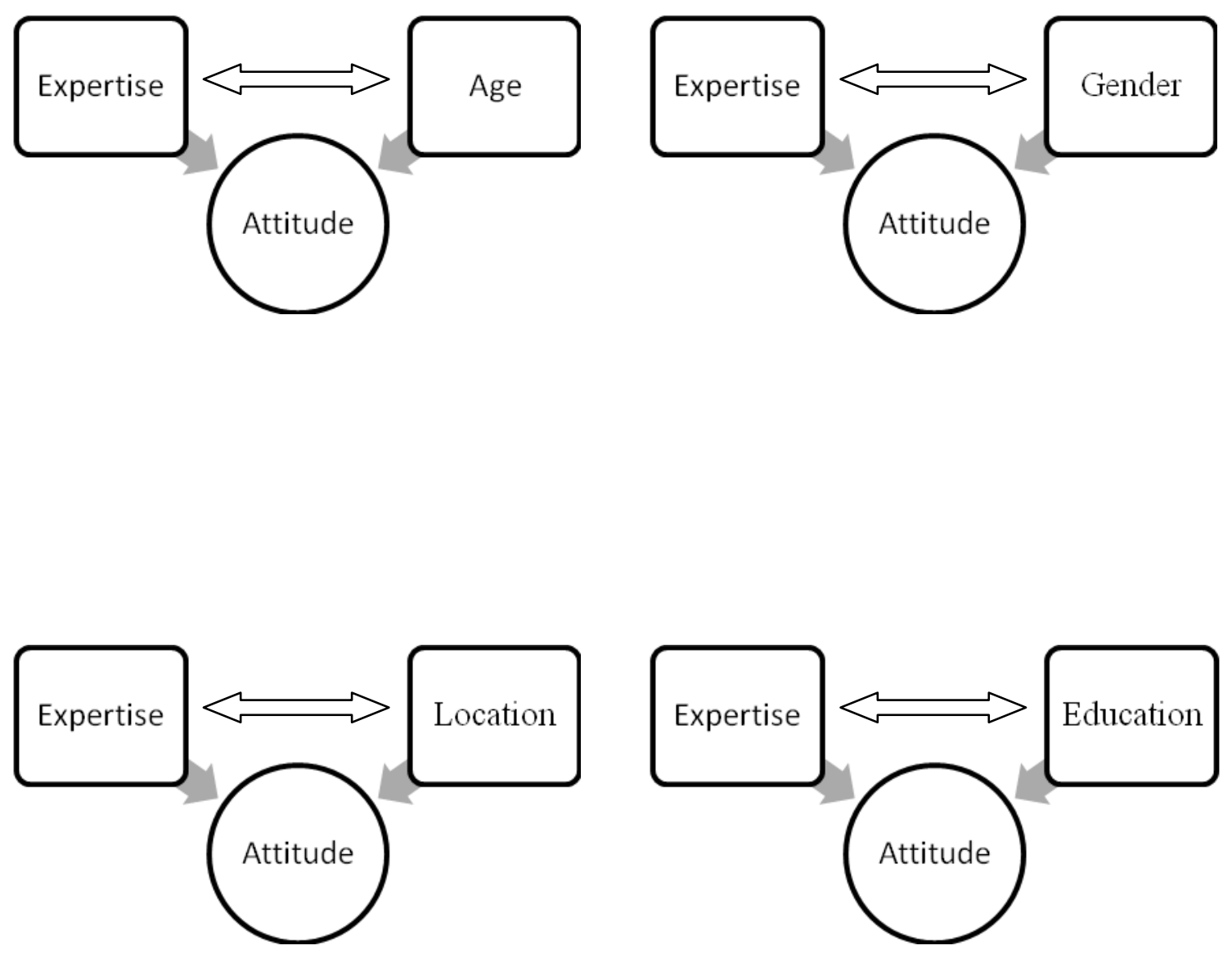
Figure 4 Independent Variable (Expertise) on Obstacles to E-government.

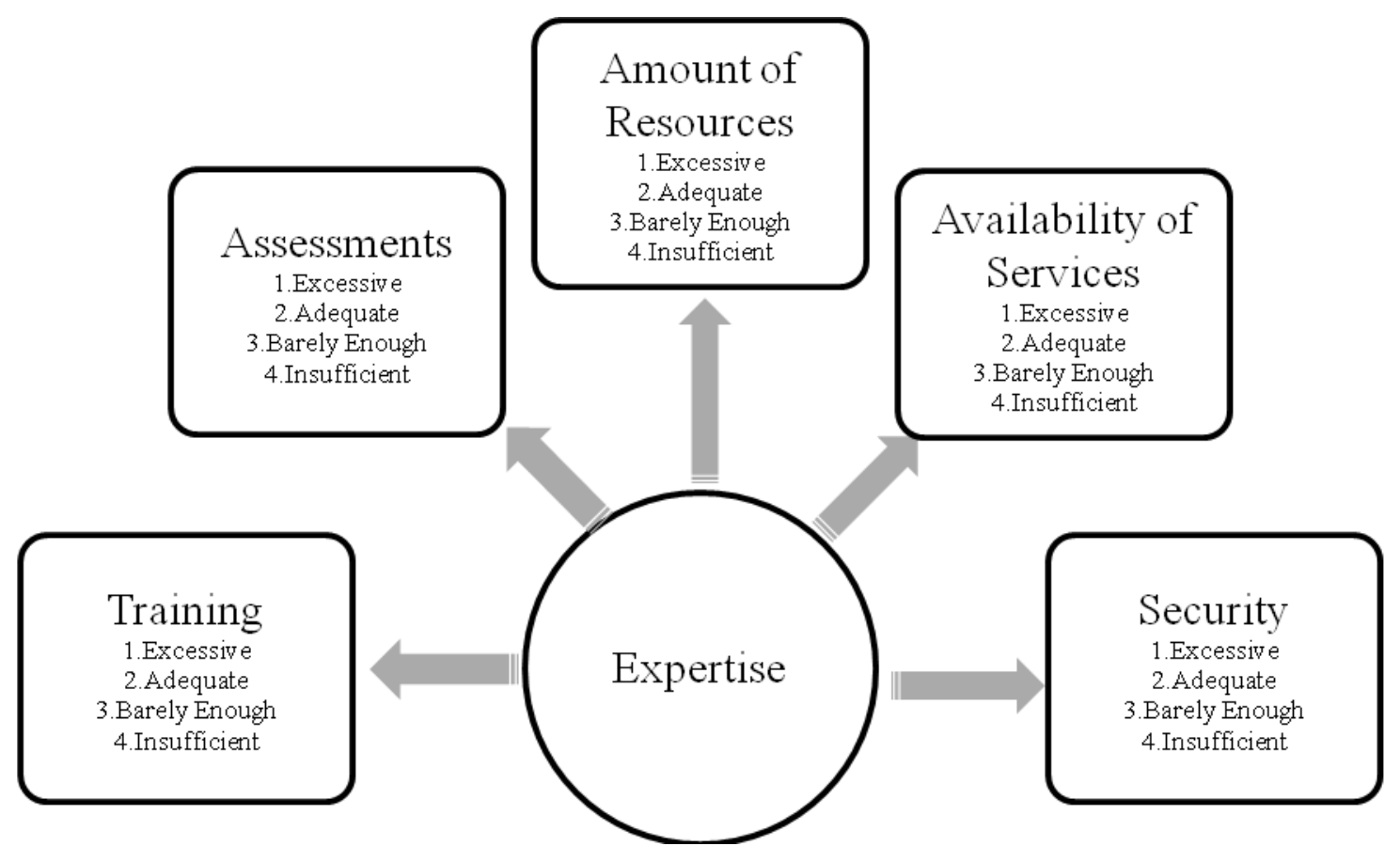




\section{Chapter 4: Analysis of Data}

\section{Introduction}

The following five research questions were used to conduct the study:

1. Is there an effect of e-technology expertise on public administrators' attitudes to e-government in general?

2. Are there effects of the demographic characteristics (age, gender, location, and education) on public administrators' attitudes to e-government in general?

3. Are there effects of the interactions of expertise with demographic characteristics (age, gender, location, and education) on public administrators' attitudes to egovernment in general?

4. Are there effects of e-technology expertise on public administrators' perceptions of the potential obstacles to e-government identified in the review of literature?

5. What items do public administrators list as potential obstacles to e-government at this time?

The main purpose of the study was to determine whether public administrators' attitudes were affected by an interaction between demographic characteristics and expertise. SPSS 15.0 was used to conduct all the statistical testing in this project. The demographic characteristics and expertise were looked at separately to show their relationship with attitude. For this, three independent-sample T-tests were used for the variables containing only two factors (age, gender, and location), and 2 one-way ANOVAs were used for the remaining variables (expertise and education). The interactional effects were looked at using 4 two-way ANOVAs. The impact of expertise on obstacles to e-government used 5 one-way ANOVAs to calculate the results. This 
chapter focuses on the descriptive and inferential statistics used to generate the answers to the five research questions.

Results

Question 1: Is there an effect of e-technology expertise on public administrators' attitudes to e-government in general?

Hypothesis ${ }_{01}$ : There is no main effect for the factor of expertise on attitudes to egovernment.

A one-way ANOVA was conducted to evaluate the null hypothesis which stated that there is no main effect for the factor of expertise on attitudes to e-government and to analyze the relationship between expertise and attitude in which the alpha was set to .05 to find the level of significance. The independent variable, expertise, contained three categories: beginner, intermediate, and advanced. The dependent variable, attitude, was an estimated numerical value calculated from the survey. Table 3 shows the descriptive statistics of mean and standard deviation for the effect of expertise on attitude. The ANOVA conducted for expertise on attitude was found to be significant, $F(2,181)=10.799, p=.000$. Due to the level of significance, a Scheffe post hoc test was conducted to find where that significance occurred. It was concluded that $\mathrm{p}<.05$ between beginner and intermediate, intermediate and advanced, and advanced and beginner (see Table 4). Due to this significance, the null hypothesis was rejected.

Question 2: Are there effects of demographic characteristics (age, gender, location, and education) on public administrators' attitudes to e-government in general?

Hypothesis ${ }_{02}$ : There is no main effect for the factor of age on attitudes to egovernment. 
These demographics were all looked at separately; therefore, four different statistical tests were used to produce results. Both descriptive statistics and inferential statistics were used to analyze these variables at which an alpha level of .05 was set. An independent-samples t-test was conducted to evaluate the null hypothesis. Table 3 shows the descriptive statistics of mean and standard deviation for the effect of age on attitude. For the factor of age on attitude, the $t$-test was significant, $t(182)=-2.783, p=.006$ (see Table 5). Due to the significance, the null hypothesis was rejected.

Hypothesis ${ }_{03}$ : There is no main effect for the factor of gender on attitudes to egovernment.

An independent-samples t-test was conducted to evaluate the null hypothesis and to analyze the relationship between gender and attitude. Table 3 shows the descriptive statistics of mean and standard deviation for the effect of gender on attitude. For the factor of gender on attitude, the $t$-test was not significant, $t(182)=1.372, p=.172$ (see Table 5). The null hypothesis failed to be rejected.

Hypothesis $_{04}$ : There is no main effect for the factor of location on attitudes to egovernment.

For null hypothesis four, an independent-samples t-test was conducted to analyze the relationship between location and attitude. Table 3 shows the descriptive statistics of mean and standard deviation for the effect of location on attitude. For the factor of location, the t-test was not significant, $\mathrm{t}(182)=.310, \mathrm{p}=.757$. The null hypothesis failed to be rejected.

Hypothesis 05 : There is no main effect for the factor of education on attitudes to egovernment. 
A one-way ANOVA was used to evaluate the relationship between level of education and attitude. The independent variable, education, contained three levels: some college, college degree, and graduate degree. The dependent variable, attitude was an estimated numerical value calculated from the survey. Table 3 shows the descriptive statistics of mean and standard deviation for the effect of education on attitude. The ANOVA conducted for education on attitude was not significant, $F(2,181)=.109, p=.897$ (see Table 4). The null hypothesis failed to be rejected.

Table 3 Mean and Standard Deviation of Expertise and Demographics on Attitude.

\begin{tabular}{|c|c|c|c|}
\hline Factor & & $\mathrm{M}$ & SD \\
\hline Expertise & $\begin{array}{l}\text { Beginner } \\
\text { Intermediate } \\
\text { Advanced }\end{array}$ & $\begin{array}{l}3.0945 \\
3.2809 \\
3.5500\end{array}$ & $\begin{array}{l}.47776 \\
.37748 \\
.28868\end{array}$ \\
\hline Age & $\begin{array}{l}\text { Over } 50 \\
50 \& \text { younger }\end{array}$ & $\begin{array}{l}3.2064 \\
3.3786\end{array}$ & $\begin{array}{l}.43108 \\
.36550\end{array}$ \\
\hline Gender & $\begin{array}{l}\text { Female } \\
\text { Male }\end{array}$ & $\begin{array}{l}3.3404 \\
3.2463\end{array}$ & $\begin{array}{l}.38932 \\
.42261\end{array}$ \\
\hline Location & $\begin{array}{l}\text { Municipality } \\
\text { County }\end{array}$ & $\begin{array}{l}3.2864 \\
3.2657\end{array}$ & $\begin{array}{l}.38025 \\
.43011\end{array}$ \\
\hline Education & $\begin{array}{l}\text { Some College } \\
\text { College Degree } \\
\text { Graduate Degree }\end{array}$ & $\begin{array}{l}3.3250 \\
3.2794 \\
3.2644 \\
\end{array}$ & $\begin{array}{l}.42573 \\
.42322 \\
.41368 \\
\end{array}$ \\
\hline
\end{tabular}

Table 4 Impact of Expertise and Education on Attitude to E-government.

\begin{tabular}{|l|l|c|}
\hline Factor & $\mathrm{F}$ & $\mathrm{P}$ \\
\hline Expertise & 10.799 & .000 \\
Beginner-Intermediate & & .029 \\
Intermediate-Advanced & & .010 \\
Advanced-Beginner & & .000 \\
\hline Education & .109 & .897 \\
Some College-College Degree & & .951 \\
College Degree-Graduate Degree & & .977 \\
Graduate Degree- Some College & & .907 \\
\hline
\end{tabular}


Table 5 Impact of Age, Gender, and Location on Attitude to E-government

\begin{tabular}{|l|l|l|}
\hline Factor & T & P \\
\hline Age & -2.783 & .006 \\
\hline Gender & 1.372 & .172 \\
\hline Location & .310 & .757 \\
\hline
\end{tabular}

Question 3: Are there effects of the interactions of expertise with demographic characteristics (age, gender, location, and education) on public administrator's attitudes to e-government in general?

Hypothesis 06 : There is no interaction effect for the factors of expertise and age on attitudes to e-government.

Four two-way ANOVAs with an alpha level set at .05 were conducted to analyze if there was an interaction between expertise and the demographic characteristics on attitude to e-government. To analyze the hypothesis, a 3x2 ANOVA was conducted with expertise having three categories: beginner, intermediate, and advanced; and age having two categories: over 50 and 50 and younger. The means and standard deviations for age and expertise are shown in Table 6. The ANOVA proved a nonsignificant main effect for age, $\mathrm{F}(1,178)=2.231, \mathrm{p}=.137$, a significant main effect of expertise, $\mathrm{F}(2,178)=5.918, \mathrm{p}=.003$, and a nonsignificant interaction effect between age and expertise, $\mathrm{F}(2,178)=.377, \mathrm{p}=.687$. Further hypothesis tests were conducted on the simple main effects. These tests showed that there were a significant difference in the over 50 age range between beginner and intermediate, intermediate and advanced, and beginner and 
advanced. In the 50 and younger age range, there was only a significant difference between intermediate and advanced (see Table 7). With these results, the null hypothesis was rejected.

Table 6 Mean and Standard Deviation of the Interactions on Attitude.

\begin{tabular}{|c|c|c|}
\hline Factors & Mean & SD \\
\hline $\begin{array}{c}\text { Age-Expertise } \\
\text { Over } 50 \\
\text { Beginner } \\
\text { Intermediate } \\
\text { Advanced } \\
50 \text { or younger } \\
\text { Beginner } \\
\text { Intermediate } \\
\text { Advanced }\end{array}$ & $\begin{array}{l}3.0593 \\
3.2427 \\
3.5250\end{array}$ & $\begin{array}{l}.48801 \\
.38395 \\
.27513 \\
\\
.39340 \\
.36588 \\
.30570\end{array}$ \\
\hline $\begin{array}{c}\text { Gender-Expertise } \\
\text { Female } \\
\text { Beginner } \\
\text { Intermediate } \\
\text { Advanced } \\
\text { Male } \\
\text { Beginner } \\
\text { Intermediate } \\
\text { Advanced }\end{array}$ & $\begin{array}{l}3.3056 \\
3.3149 \\
3.5417 \\
\\
3.0418 \\
3.2658 \\
3.5526\end{array}$ & $\begin{array}{l}.39087 \\
.38351 \\
.43060 \\
\\
.48756 \\
.37626 \\
.24408\end{array}$ \\
\hline $\begin{array}{c}\text { Location-Expertise } \\
\text { Municipality } \\
\text { Beginner } \\
\text { Intermediate } \\
\text { Advanced } \\
\text { County } \\
\text { Beginner } \\
\text { Intermediate } \\
\text { Advanced }\end{array}$ & $\begin{array}{l}3.0703 \\
3.2960 \\
3.5167\end{array}$ & $\begin{array}{l}.46315 \\
.34480 \\
.17480 \\
\\
.48872 \\
.39047 \\
.34675\end{array}$ \\
\hline $\begin{array}{c}\text { Education-Expertise } \\
\text { Some College } \\
\text { Beginner } \\
\text { Intermediate } \\
\text { Advanced } \\
\text { College Degree } \\
\text { Beginner } \\
\text { Intermediate } \\
\text { Advanced } \\
\text { Graduate Degree } \\
\text { Beginner } \\
\text { Intermediate } \\
\text { Advanced }\end{array}$ & $\begin{array}{l}3.2000 \\
3.2197 \\
3.6250 \\
\\
3.0470 \\
3.3036 \\
3.5156\end{array}$ & $\begin{array}{l}.46845 \\
.38404 \\
.40089 \\
\\
.48981 \\
.36751 \\
.23218\end{array}$ \\
\hline
\end{tabular}


Table 7 Impact of the Interaction of Demographics and Expertise on Attitude.

\begin{tabular}{|c|c|c|}
\hline Factors & $\mathrm{F}$ & $\mathrm{P}$ \\
\hline $\begin{array}{l}\text { Age-Expertise } \\
\text { Over } 50 \\
\text { Beginner-Intermediate } \\
\text { Intermediate-Advanced } \\
\text { Beginner-Advanced } \\
50 \text { or younger } \\
\text { Beginner-Intermediate } \\
\text { Intermediate-Advanced } \\
\text { Beginner-Advanced }\end{array}$ & $\begin{array}{l}5.231 \\
4.462 \\
11.071 \\
\\
.089 \\
4.012 \\
2.429\end{array}$ & $\begin{array}{r}.023 \\
.036 \\
.001 \\
\\
.765 \\
.047 \\
.121\end{array}$ \\
\hline $\begin{array}{l}\text { Gender-Expertise } \\
\text { Female } \\
\text { Beginner-Intermediate } \\
\text { Intermediate-Advanced } \\
\text { Beginner-Advanced } \\
\text { Male } \\
\text { Beginner-Intermediate } \\
\text { Intermediate-Advanced } \\
\text { Beginner-Advanced }\end{array}$ & $\begin{array}{l}.004 \\
1.700 \\
1.295 \\
\\
8.010 \\
8.130 \\
20.943\end{array}$ & $\begin{array}{l}.950 \\
.194 \\
.257 \\
\\
.005 \\
.005 \\
.000\end{array}$ \\
\hline $\begin{array}{l}\text { Location-Expertise } \\
\text { Municipality } \\
\text { Beginner-Intermediate } \\
\text { Intermediate-Advanced } \\
\text { Beginner-Advanced } \\
\text { County } \\
\text { Beginner-Intermediate } \\
\text { Intermediate-Advanced } \\
\text { Beginner-Advanced }\end{array}$ & $\begin{array}{l}.456 \\
6.207 \\
7.150 \\
\\
7.459 \\
3.930 \\
12.948\end{array}$ & $\begin{array}{l}.500 \\
.014 \\
.008 \\
\\
.007 \\
.049 \\
.000\end{array}$ \\
\hline $\begin{array}{l}\text { Education-Expertise } \\
\text { Some College } \\
\text { Beginner-Intermediate } \\
\text { Intermediate-Advanced } \\
\text { Beginner-Advanced } \\
\text { College Degree } \\
\text { Beginner-Intermediate } \\
\text { Intermediate-Advanced } \\
\text { Beginner-Advanced } \\
\text { Graduate Degree } \\
\text { Beginner-Intermediate } \\
\text { Intermediate-Advanced } \\
\text { Beginner-Advanced }\end{array}$ & $\begin{array}{l}.019 \\
6.696 \\
5.082 \\
\\
9.349 \\
3.753 \\
14.829 \\
\end{array}$ & $\begin{array}{l}.891 \\
.010 \\
.025 \\
\\
.003 \\
.054 \\
.000\end{array}$ \\
\hline
\end{tabular}


Hypothesis 07: There is no interaction effect for the factors of expertise and gender on attitudes to e-government.

A 3x2 ANOVA was conducted with expertise and gender having two categories: female and male. The means and standard deviations for gender and expertise are located in Table 6. The ANOVA indicated a nonsignificant main effect for gender, $\mathrm{F}(1,178)=1.472, \mathrm{p}=.227$, a significant main effect for expertise, $\mathrm{F}(2,178)=5.107, \mathrm{p}=.007$, and a nonsignificant interaction effect between gender and expertise, $\mathrm{F}(2,178)=.979$, $\mathrm{p}=.378$. Further hypothesis tests were conducted on the simple main effects. These tests showed that there were no significant differences between levels of expertise in females. There were significant differences between all levels of expertise in males (see Table 7). Due to these significant differences, the null hypothesis was rejected.

Hypothesis ${ }_{08}$ : There is no interaction effect for the factors of expertise and location on attitudes to e-government.

To analyze this hypothesis, a 3×2 ANOVA was used with expertise and location with location having two categories: city and county. The means and standard deviations for location and expertise are shown in Table 6. The ANOVA indicated that there was no significant effect for location, $F(1,178)=.257, p=.613$, a significant effect for expertise, $F(2,178)=9.256, p=.000$, and a nonsignificant interaction effect between expertise and location, $\mathrm{F}(2,178)=.551, \mathrm{p}=.577$. The hypothesis tests conducted on the simple main effects showed that there was a significant difference between intermediate and advanced, and beginner and advanced in cities. In the county positions, there was a significant difference between all levels of expertise (see Table 7). The null hypothesis was rejected due to these significant differences. 
Hypothesis ${ }_{09}$ : There is no interaction effect for the factors of expertise and education on attitudes to e-government.

A 3x3 ANOVA was used with expertise having three categories and education having three categories: some college, college degree, and graduate degree. The means and standard deviations for education and expertise are shown in Table 6. The ANOVA proved a nonsignificant main effect for education, $\mathrm{F}(2,175)=.332$, $\mathrm{p}=.718$, a nonsignificant main effect for expertise, $\mathrm{F}(2,175)=2.514, \mathrm{p}=.084$, and a nonsignificant interaction effect between education and expertise, $F(4,175)=.703, p=.591$. Hypothesis testing was done to look for significance in the simple main effects. These tests showed that with the college degree category, a significant difference existed between intermediate and advanced, and beginner and advanced. A significant difference also existed between beginner and intermediate, and beginner and advanced with a graduate degree (see Table 7). The null hypothesis was rejected due to these results.

Question 4: Are there effects of e-technology expertise on public administrators' perceptions of the potential obstacles to e-government identified in the review of literature.

Research question four asks if there are effects of e-technology expertise on public administrators' perceptions of the potential obstacles to e-government identified in the review of literature. Five one-way ANOVAs were conducted to determine the relationship between the independent variable, expertise, and the dependent variables of amount of resources, availability of services, security, assessments, and training with an alpha level set at .05 to find the level of significance. The independent variable of expertise contains three categories: beginner, intermediate, and advanced. The dependent 
variables' scores were derived from a scale of 1-4 with 1=excessive, $2=$ adequate, 3=barely enough, and 4=insufficient. An estimated value was taken into account for each obstacle and participant. For each obstacle, descriptive and inferential statistics were done to show the effects.

Hypothesis $_{10}$ : There is no main effect for the factor of expertise on public administrators' perceptions of the obstacle of resources to e-government.

As was stated before, a one-way ANOVA was performed to evaluate this null hypothesis and to analyze the relationship between level of expertise and the perceptions of the amount of resources available to e-government. The mean and standard deviation for the effect of expertise on the perception of the amount of resources available are shown in Table 8. The ANOVA conducted for expertise on the amount of resources available was found to be not significant, $F(2,181)=.273$, $\mathrm{p}=.761$ (see Table 9). Since the ANOVA was not significant, further testing of a post hoc was not performed. The null hypothesis failed to be rejected. 
Table 8 Mean and Standard Deviation of Expertise on Obstacles to E-government.

\begin{tabular}{|c|l|l|}
\hline Obstacles & M & SD \\
\hline $\begin{array}{c}\text { Amount of Resources } \\
\text { Expertise }\end{array}$ & & \\
Beginner & 2.69 & .701 \\
Intermediate & 2.69 & .680 \\
Advanced & 2.80 & .645 \\
\hline Availability of Services & & \\
Expertise & & \\
Beginner & 2.67 & .674 \\
Intermediate & 2.79 & .631 \\
Advanced & 2.88 & .666 \\
\hline Security & & \\
Expertise & & \\
Beginner & 2.38 & .614 \\
Intermediate & 2.39 & .619 \\
Advanced & 2.48 & .586 \\
\hline Assessments & & \\
Expertise & & \\
Beginner & 2.64 & .712 \\
Intermediate & 2.68 & .672 \\
Advanced & 2.64 & .569 \\
\hline Training & & \\
Expertise & & .677 \\
Beginner & 2.89 & \\
Intermediate & 2.84 & \\
Advanced & & \\
\hline
\end{tabular}


Table 9 Impact of Expertise on Obstacles to E-government.

\begin{tabular}{|c|l|c|}
\hline Obstacles & $\mathrm{F}$ & $\mathrm{P}$ \\
\hline Amount of Resources & .273 & .761 \\
Expertise & & .999 \\
Beginner-Intermediate & .777 \\
Intermediate-Advanced & & .808 \\
Advanced-Beginner & & \\
\hline Availability of Services & .989 & .374 \\
Expertise & & .559 \\
Beginner-Intermediate & & .818 \\
Intermediate-Advanced & .418 \\
Advanced-Beginner & & \\
Security & .245 & .783 \\
Expertise & & .988 \\
Beginner-Intermediate & .820 \\
Intermediate-Advanced & & .800 \\
Advanced-Beginner & & \\
Assessments & .052 & .950 \\
Expertise & & .966 \\
Beginner-Intermediate & .972 \\
Intermediate-Advanced & & 1.000 \\
Advanced-Beginner & & \\
Training & .160 & .853 \\
Expertise & & .921 \\
Beginner-Intermediate & .959 \\
Intermediate-Advanced & & \\
Advanced-Beginner & & .862 \\
\hline
\end{tabular}

Hypothesis ${ }_{11}$ : There is no main effect for the factor of expertise on public administrators' perceptions of the obstacle of public access to e-government.

A one-way ANOVA was conducted to analyze the null hypothesis and the relationship between the independent variable of expertise and the dependent variable of availability of services. The mean and standard deviation for the effect of expertise on the perception of public access are shown in Table 8. The ANOVA conducted was not significant, $F(2,181)=.989, \mathrm{p}=.374$ (see Table 9). Since there was no significance, further testing was not conducted. The null hypothesis failed to be rejected. 
Hypothesis ${ }_{12}$ : There is no main effect for the factor of expertise on public administrators' perceptions of the obstacle of security to e-government.

A one-way ANOVA was performed to evaluate the null hypothesis and to analyze the relationship between the independent variable of expertise and the dependent variable of security. Table 8 shows the mean and standard deviation calculated for the effect of expertise on security. The ANOVA conducted was not significant, $F(2,181)=.245$, $\mathrm{p}=.783$ (see Table 9). Due to the ANOVA having no significance, a post hoc test was not performed. The null hypothesis failed to be rejected.

Hypothesis ${ }_{13}$ : There is no main effect for the factor of expertise on public administrators' perceptions of the obstacle of assessments to e-government.

To analyze the null hypothesis and the relationship between the independent variable of expertise and the dependent variable of assessments a one-way ANOVA was used. Table 8 shows the mean and standard deviation calculated for the effect of expertise on assessments. The ANOVA performed was not significant, $\mathrm{F}(2,181)=.052$, $\mathrm{p}=.950$ (see Table 9). Because the ANOVA proved to be not significant, the null hypothesis failed to be rejected.

Hypothesis 14: There is no main effect for the factor of expertise on public administrators' perceptions of the obstacle of training to e-government.

A one-way ANOVA was conducted to evaluate the null hypothesis and the relationship between the independent variable, expertise, and the dependent variable, training. The mean and standard deviation for the effect of expertise on the perception training of personnel are shown in Table 8. The ANOVA conducted was not significant, 
$\mathrm{F}(2,181)=.160, \mathrm{p}=.853$ (see Table 9). Since the ANOVA was not significant, further testing of a post hoc was not performed. The null hypothesis failed to be rejected.

\section{Data Coding}

Question 5: What items do public administrators list as potential obstacles to egovernment at this time?

Research question five asks what items public administrators listed as potential obstacles to e-government at this time. A qualitative approach was taken to determine the obstacles that the participants believed to affect the development of e-government. Out of the 184 total participants in the study, 118 entered one to three comments on the obstacles section of the survey. This is a general view of obstacles to e-government; therefore, demographics were not considered. A total of 210 responses were used in the analysis of potential obstacles to e-government. Table 4 shows the number of responses for each obstacle as well as the percentage of each obstacle in terms of total responses. The obstacle of cost included responses dealing with funds, budgets, and resources of the government. Security revolved around responses pertaining to too much information being available through the internet. This list included credit card numbers for payments and personal records being accessible. Training ranged from educating the public to training employees. It also included such things as skills, knowledge of e-government, knowledge of the public, and expertise. This last grouping was placed in training because most of these obstacles are or can be dependent upon available training. Resistance to change included the public and government employees' unwillingness to adapt to the changing technology and also acceptance of new technological ways. Availability was aimed at both the public and the government. It included access to equipment including 
internet service in rural areas, computers, and software. Time, an added theme, involved such concerns over the ability to keep up with the changing technology as well as time to develop and implement e-government. Personal interaction dealt with the concern of dehumanizing services; many citizens may continue to want face-to face communication. The last theme presented, digital divide, included issues such as age, younger people more willing to use technology, and the reluctance of older employees.

To analyze the data, a coding process was performed to determine the most frequent obstacle themes. The coding process was conducted three different times to provide the most accurate themes. To begin, five common themes of obstacles of technology use were selected based on the literature review and personal experience and feelings. Those five themes included: cost, security, training, resistance to change, and availability of technology. The first process of coding began by analyzing the list of each participant and placing the obstacle under the best theme. It was also important to look at each obstacle to determine if other themes needed to be created based on the list. Through the first process, it was found that the five main themes were frequent obstacles listed by the participants on the survey; however, three other themes emerged which included: time, knowledge, and personal interaction. These three themes were added to the original five for the second process of coding. The second round of coding followed the same process as the first with the new additions. This second time determined two more themes that occurred often: knowledge and digital divide. During the first process, knowledge was placed under training, but there was a significant number involving just knowledge that it was appropriate to create it as a separate category. Also, digital divide was placed under resistance to change, but it was decided that age is not necessarily a 
factor in the resistance to change. The third and final process was conducted the same as the first two with the exception of a total of nine themes. During the third process, a close analysis was taken on the items listed under the added themes. Time, personal interaction, and digital divide all had items that could not belong in the original five themes; however, the items listed under knowledge could be combined with the items listed under training to create one large category.

Table 10 List of Potential Obstacles

\begin{tabular}{|l|c|c|}
\hline \multicolumn{1}{|c|}{ Obstacles } & Responses & Percentage \\
\hline Cost & 70 & $33.3 \%$ \\
\hline Security & 30 & $14.3 \%$ \\
\hline Training & 39 & $18.6 \%$ \\
\hline Resistance to Change & 17 & $8.1 \%$ \\
\hline Availability of Technology & 28 & $13.3 \%$ \\
\hline Time & 11 & $5.2 \%$ \\
\hline Personal Interaction & 7 & $3.3 \%$ \\
\hline Digital Divide & 8 & $3.8 \%$ \\
\hline Totals & $\mathbf{2 1 0}$ & $\mathbf{9 9 . 9 \%}$ \\
\hline
\end{tabular}

Total does not reach $100 \%$ due to rounding. 


\section{Chapter 5: Summary, Discussion, and Conclusion}

\section{Summary}

With the development of technology growing rapidly over the past twenty years, the need to modify many different disciplines has also increased. Technology is spreading into all aspects of life such as education, business, and government. One of the emerging technology themes is in the field of e-government. This is fairly new in development with very little research focused on the many factors that can affect the adoption of such technology in government. The majority of research that has been conducted has focused solely on generational issues and the relationship of age with the acceptance of technology. While age is an important factor in the field of e-technology, other factors may have significant importance as well, especially on the attitude and perceptions of the developing technology. Therefore, in addition to age it is important to explore other demographics such as gender, location, and education as well as expertise to determine the effect that each of these factors has on the attitude towards technology, particularly the implementation of it in government.

The three main goals of this study were the following: to determine the effects of demographic characteristics and the factor of expertise on general attitudes to egovernment, to determine the effects of expertise on participants' evaluations of the five main obstacle issues identified in the review of e-government literature, and to allow participants to also provide written suggestions about the obstacles to e-government. To address these goals, five research questions were asked:

1. Is there an effect of e-technology expertise on public administrators' attitudes to e-government in general? 
2. Are there effects of the demographic characteristics (age, gender, location, and education) on public administrators' attitudes to e-government in general?

3. Are there effects of the interactions of expertise with demographic characteristics (age, gender, location, and education) on public administrators' attitudes to e-government in general?

4. Are there effects of e-technology expertise on public administrators' perceptions of the potential obstacles to e-government identified in the review of literature?

5. What items do public administrators list as potential obstacles to egovernment at this time?

The first four research questions were evaluated using quantitative research methods and the last question took a different approach with qualitative research methods. To address the first four questions, various statistical methods were set up in SPSS 15.0. For question one, a one-way ANOVA was conducted to analyze the effect of the independent variable, expertise, on the dependent variable, attitude. T-tests and a oneway ANOVA were used to evaluate the effect of the demographic characteristics separately on attitude in question two. Question three used 4 two-way ANOVAs to determine the interactional effect between demographic characteristics and expertise on attitude. For question four, 5 one-way ANOVAs with expertise acting as the independent variable and each obstacle acting as the dependent variable were used. For each of the statistical methods, an alpha of .05 was set to determine the level of significance. In addition to the inferential statistics, descriptive statistics were also used to analyze each 
question. The final question was evaluated using a data coding system to determine the themes that participants found to be obstacles to e-government.

\section{Findings}

This study determined that when expertise was looked at alone, all levels of expertise had a somewhat positive attitude to e-government [Total (M=3.2719)].

Advanced administrators had a more positive attitude to e-government than intermediate $(\mathrm{M}=3.2809)$ and beginner $(\mathrm{M}=3.0945)$ administrators. However, while all the levels of expertise had an overall positive attitude to e-government, there were differences between the levels that did exist. The biggest difference occurred between beginner and advanced participants with advanced administrators having a more positive attitude, while the smallest difference was between intermediate and beginner with beginners having a less positive attitude to e-government. This suggests that although all levels of expertise may have a positive attitude to e-government, a gap still exists which shows that expertise does affect attitude to e-government. These results are supported by the Lenhart (2000) study. Lenhart found that older users are less likely to use technology and more resistant to adopting technology use. While this study mainly focused on the issue of age on attitude, it also showed that participants with less expertise have a less positive attitude to e-technology.

In addition to expertise being looked at separately, the demographic characteristics were analyzed alone to determine their effect on attitude without interactions. When looking at age, it was determined that the 50 and younger participants had an overall somewhat positive attitude to e-government $(M=3.3786)$ while the over 50 administrators $(M=3.2064)$ were slightly less positive. It was also revealed that a 
significant difference does exist between the two age groups in terms of attitude to egovernment. In the category of gender, female administrators $(\mathrm{M}=3.3404)$ were overall positive to e-government while males $(M=3.2463)$ were slightly less positive to egovernment. However, it was determined between the two groups that there was no significant difference; therefore, gender is not a key factor in defining attitude to egovernment. Administrators in a municipality setting $(\mathrm{M}=3.2864)$ as well as a county setting $(M=3.2657)$ were somewhat positive to e-government. Also, there was no significant difference between the two location groups which suggest that location does not play an important role in affecting the attitude to e-government. The overall attitude of administrators in terms of education was somewhat positive $(\mathrm{M}=3.2719)$. Those with some college $(\mathrm{M}=3.3250)$ rated e-government more positively than those with a college degree $(M=3.2794)$ and those with a graduate degree $(M=3.2644)$. However, there was no significant difference between the three groups of educational levels which suggests that it does not influence the attitudes to e-government alone. With the exception of age, there were no previous studies found to support the results of the effects of the demographic characteristics on attitude. However, studies performed by Morris (1989); Baack, Brown, and Brown (1991); Lenhart (2000); and DeOllos and Morris (2004) all support the results that the older generation has a more negative attitude to e-government than the younger generation.

When the interactions between the demographic characteristics and expertise were looked at, it was determined that some interactions do affect the attitude to egovernment. In the interactional effect between expertise and age, it was proven that in the over 50 category beginner administrators $(M=3.0593)$ were less positive than 
intermediate administrators $(\mathrm{M}=3.2427)$ and out of the three subcategories, advanced administrators $(\mathrm{M}=3.5250)$ had an overall more positive attitude to e-government. It was also shown in the over 50 category that all the levels of expertise were significantly different. In the 50 and younger category, beginner administrators $(M=3.2857)$ had an overall somewhat positive attitude to e-government, intermediate administrators $(\mathrm{M}=3.3333)$ had a slightly more positive attitude overall, and advanced administrators $(M=3.5667)$ had an even more positive attitude to e-government. However, when looking at the interaction between the category of 50 or younger and between the expertise levels, it was proven that a difference existed only between intermediate and advanced. These results suggest that while all levels of expertise within both age categories show a somewhat positive to very positive attitude, the interactions between age and expertise can affect an administrators' attitude to e-government. These results are supported by the Chen-Persson (2002) study which found that older adults who had more expertise with technology had a more positive attitude to e-technology.

It was also shown that in the interaction of gender and expertise, beginner female administrators $(M=3.3056)$ and intermediate female administrators $(M=3.3149)$ had similar somewhat positive responses to the attitude section of the survey. However, advanced female administrators $(\mathrm{M}=3.5417)$ had a more positive attitude to egovernment. There were no significant differences between the levels of expertise within the female category. With male administrators, advanced participants $(M=3.5526)$ were overall positive to e-government with intermediate administrators ( $M=3.2658)$ less positive in their responses, and beginner administrators $(M=3.0418)$ the least positive in their responses to attitude. The results also showed that there is an interactional effect 
between all levels of expertise and the male category. This suggests that interactions between gender and expertise can influence the attitude.

The results of the interaction of location and expertise showed that expertise may play a role in influencing attitude. Advanced administrators in both a municipality setting $(M=3.600)$ and county setting $(M=3.5167)$ had a positive attitude to e-government. Intermediate administrators in a municipality setting $(\mathrm{M}=3.2422)$ and a county setting $(\mathrm{M}=3.2960)$ were less positive than the advanced administrators. Beginner administrators $(\mathrm{M}=3.1542)$ in a municipality and a county $(\mathrm{M}=3.0703)$ both were less positive than the intermediate administrators. Also, the significant differences between the interaction of location and expertise showed that the only group that a significant difference did not exist is between beginner and intermediate administrators in a municipality setting.

In the interaction between education and expertise, advanced administrators in the categories of some college $(M=3.5000)$, college degree $(M=3.6250)$, and graduate degree $(\mathrm{M}=3.5156)$ were highly positive in their attitude to e-government. Intermediate administrators with some college $(\mathrm{M}=3.3333)$, a college degree $(\mathrm{M}=3.2197)$, and a graduate degree $(\mathrm{M}=3.3036)$ had a somewhat positive attitude to e-government. Beginner administrators with some college $(M=3.2500)$, a college degree $(M=3.2000)$, and a graduate degree $(M=3.0470)$ were least positive in their attitudes to e-government. It was proven that significant differences did exist between intermediate and advanced, and beginner and advanced with a college degree; and also between beginner and intermediate, and beginner and advanced with a graduate degree. This showed that expertise can impact the effect of education on attitude. 
While the interaction effect of age and expertise on attitude was supported by the review of literature, no other previous studies were found that looked at the interactional effects of the other demographics and expertise. Expertise was chosen as the moderating factor in the interactional effects because many studies considered it as a confounding variable that may affect the outcome of the demographic characteristics on attitude, which was found to be true. This study focused on these interactional effects due to the fact that there is a lack of information about these interactions on attitude in the field of egovernment.

The findings from question two and question three showed that there are interactional effects of demographic characteristics and expertise on public administrators' attitudes to e-government in general. Age was the only demographic characteristic that had an effect on attitudes alone. Gender, location, and education did not have an effect on public administrators' attitudes to e-government when they were looked at in a non-interactional situation. However, overall, when expertise was added to each of the demographics it was determined that an effect occurred. The level of expertise and age, the level of expertise and gender, the level of expertise and location, and the level of expertise and education did impact the attitude that administrators had to e-government. In conclusion, administrators classified as beginners in their expertise had the least positive attitude to e-government. The administrators categorized as intermediate in their expertise were more positive, and advanced administrators in their expertise were the most positive in all demographic categories.

This study also analyzed the effects of expertise on obstacles to e-government. The results indicated expertise did not play a role in administrators' perceptions of 
obstacles to e-government. Beginner $(\mathrm{M}=2.69)$, intermediate $(\mathrm{M}=2.69)$, and advanced $(\mathrm{M}=2.80)$ administrators felt that the amount of resources available for e-government was barely enough. Beginner ( $M=2.67)$, intermediate (2.79), and advanced $(M=2.88)$ administrators felt that the availability of e-government services was barely enough. Beginner $(M=2.38)$, intermediate $(M=2.39)$, and advanced $(M=2.48)$ perceived the security in government technology as adequate. Beginner $(M=2.64)$, intermediate $(\mathrm{M}=2.68)$, and advanced $(\mathrm{M}=2.64)$ administrators viewed the assessments of egovernment at this time as barely enough. Beginner $(M=2.89)$, intermediate $(M=2.84)$, and advanced $(M=2.80)$ administrators believed that the training of personnel to use egovernment technology was barely enough. These findings showed that expertise does not have an influence on the way administrators view obstacles at this time. There were no previous studies found that looked at the direct impact of expertise on the obstacles; however, the review of literature was used to determine the obstacles that would be used in question four. The obstacles found in the literature review included public access (availability of e-government services), limited resources (amount of resources available), security (security in government technology), and assessment (assessments of egovernment services). Training was added to the list because it was a common theme found throughout many studies.

Question five was analyzed using qualitative research methods. The data coding method showed that the majority of administrators viewed cost, training, security, and availability of resources as the biggest obstacles to adopting e-government at this time. The administrators also believed that the resistance to change, personal interaction, time, and the digital divide were also obstacles to consider when implementing e-government. 
These results to the qualitative section of the study are supported by various studies from the review of literature. Moulder (2001) and General Accounting Office (2007) of the United States of America both found that issues dealing with financial resources were a top obstacle in e-government. Strohm(2007); Wilshusen(2007); and Hart-Teeter (2003) both found that security was a major weakness of e-government. Wilhelm, Carmen, and Reynolds (2002); and Brescia and Daily(2007) both describe how the digital divide is an obstacle to public access of e-government. The obstacles presented by the administrators in this study are overall consistent with those in the review of literature.

\section{Implications for Public Administrators}

The findings from this study can help public administrators understand the gaps, obstacles, and challenges that they face in e-government. When the public administrators and governments start to understand the situation, they can address the problems that researchers find. The first implication for public administrators involves the study as a whole. Through this study, the research into the differences of demographics, expertise, and attitude can help administrators understand the differences that exist in their discourse community. It is important for them to first realize that the administrators throughout governments are of many different ages, female and male, city and county, different levels of education, and classified from beginner to advanced in their expertise. In addition, the attitudes of administrators can determine how willing they will be in implementing e-government in their local governments.

This study has shown that gaps do exist in attitudes. The attitudes of the administrators are dependent upon their demographics and expertise. It is important for researchers to analyze these gaps and find methods for reducing these gaps for public 
administrators. The findings from the study suggest that training is important for reducing the gaps between attitudes. In each of the interactional tests run, expertise played a significant part in creating more positive attitudes to e-government. It showed that administrators with advanced expertise had an overall very positive attitude to egovernment across all demographics. Public administrators and governments should look at these results and see that more training is needed. With more training available to the public administrators that work in these governments, their individual expertise will be raised which will cause an increase in positive attitudes to e-government according to the results of this study. This increase in positive attitude will create an environment for successful implementation of e-government.

The obstacles found in both the quantitative and qualitative part of the study provide the final implications for public administrators. The findings show that expertise did not have an effect on obstacles. The administrators regardless of their expertise described each obstacle about the same way. All the obstacles in the quantitative section were viewed as "barely enough" with the exception of security which was described as "adequate". In the qualitative section, public administrators provided a list that they viewed as potential obstacles. The top three answers included cost, training, and security. These obstacles are consistent with the ones used in the quantitative section, which suggest that the governments need to address and find solutions for these obstacles before full implementation can occur.

\section{Conclusion and Future Research}

This study has shown that expertise and demographic characteristics can impact the public administrators' attitudes to e-government. It is important to research these 
attitudes and the factors that can affect these perceptions in order to understand the gaps that exist in the administrators' discourse communities and create ways to reduce these differences. E-government is a new and emerging field in e-technology that needs to be analyzed in order to ease the implementation when it happens. A start to analyzing egovernment is by understanding the administrators who will be working with it directly. This includes looking at the administrators' expertise, demographic characteristics, attitudes, and views of potential obstacles which this study evaluated.

While analyzing the interactional effect of expertise and demographic characteristics was the main objective of this study, there is room for more research in the field of attitudes to e-government. This study only focused on the interactional effect of expertise with the demographic characteristics. It did not analyze the interactions of all the demographic characteristics with one another. It is important to see all interactions that could affect the attitude to e-government in order to understand the field more. Expertise was proven the most significant factor when looked at in a non-interactional situation on attitudes. Age was also significant in a non-interactional situation on public administrator's attitudes to e-government. Therefore, it may also be a powerful moderating factor for an interactional effect in this study. In addition, there may be other combinations of demographic characteristics that prove to be effective on attitudes. Furthermore, this study only focused on the demographic characteristics of age, gender, location, and education and not all possible demographics. Other demographic characteristics should be considered in future research.

The impact of expertise on the obstacles of e-government was also analyzed in this study; however, it is important to see any possible effects that could impact the 
perceptions of obstacles. Therefore, this part of the study should be repeated in the future using a variety of interactional combinations to determine if demographics can have an effect on obstacles like they can on attitudes. In addition, only five obstacles identified in the review of literature were used in this study. Future studies should look at a variety of obstacles such as the ones listed by the administrators in this study.

A final recommendation for future research is to increase the sample size used. The sample included only administrators who are members of ICMA. This excluded participants who are not members of ICMA and could be important administrators in analyzing. In addition, the sample within each demographic category was not equivalent. For example, there were more male than female participants, more over 50 than 50 and younger, and more county than municipality. For future studies, it would more effective to have a larger sample size to create more equal subcategories within the demographics.

As the technology "renaissance" develops and the younger generation with more computer skills takes more administrative positions alongside the older generation, the gaps that exist between the two generations in terms of expertise, acceptance, performance, and perception may increase. Possible solutions for these gaps in etechnology performance are important for the development of modern society. In order for e-government to become readily accessible for the population, studies should be conducted to determine what differences in accessibility exist, and what measures should be taken to adapt these technologies to accommodate all generations. Until the gaps are resolved, technology will remain an inaccessible part of modern life for many people. 


\section{References}

Bacher, G. (2002). E-government. For better or worse. PA Times, 25, 5-8.

Baker, D. L. \& Roach, C. M. (2007). Internet red resign: GENI's e-government implications. PA Times, 30, 7-7.

Bovens, M., \& Zouridis, S. (2002). From street-level to system-level bureaucracies: How information and communication technology is transforming administrative discretion and constitutional control. Public Administration Review, 62, 174-184.

Brescia, W., \& Daily, T. (2007) Economic development and technology-skill needs on American Indian reservations. American Indian Quarterly, 31, 23-43.

Campos, A. and Sueiro, E., 1993. Sex and age differences in visual imagery vividness. Journal of Mental Imagery 17 3-4, pp. 91-94.

Carter, L. \& Belanger, F. (2005). The utilization of e-government services: Citizen trust, innovation and acceptance factors. Information Systems Journal, 15, 5-25.

Cerella, J. (1990). Age and information processing rate. In J. E. Birren \& K. W Schaie (Eds.), Handbook of the psychology of aging (3rd ed., pp. 201-211). San Diego, CA: Academic Press.

Chen, Y. \& Persson, A. (2002). Internet use among young and older adults: Relation to psychological well-being. Educational Gerontology, 28, 731-744.

Cherry K.E., Park D.C. \& Donaldson H. (1993) Adult age differences in spatial memory: effects of structural contents and practices. Experimental Aging Research 19, $333-350$.

CMA Management. (2001). Use of e-government services on the rise. CMA Management, 75, 8-8. 
Colley, A. \& Comber, C. (2003) Age and gender differences in computer use and attitudes among secondary school students: What has changed? Educational Research, 45, 155-165.

Community Banker (2000). Bet on baby boomers when it comes to technology. Community Banker, 9, 45-45.

Conklin, W. \& Robbins-McNeish, N. (2007). Diversity toolbox: The evolution of elearning in diversity. The Diversity Factor, 15, 33-40.

Crenshaw, E. M. \& Robison, K. K. (2006). Globalization and the digital divide: The roles of structural conduciveness and global connection in internet diffusion. Social Science Quarterly, 87, 190-207.

Crossan, B., Martin, I., Whittaker, S. (2001). Learning, identity, and citizenship: Researching older people's use of ICT in Scotland. ERIC, 1-12.

Crowe, D. (2001). Generation Gap. Wireless Review, 18, 82-84.

Czaja, S. J., \& Sharit, J. (1993). Age differences in the performance of computer-based work. Psychology and Aging, 8(1), 59-67.

Dobransky, K. \& Estzer, H. (2006). The disability divide in internet access and use. Information, Communication \& Society, 9, 313-334.

Dutton, W., Guerra, G. A., Zizzo, D. J., \& Peltu, M. (2005). The cyber trust tension in Egovernment: Balancing identity, privacy, security. The International Journal of Government \& Democracy in the Information Age, 10, 13-23.

Echt, K. V., Morrell, R. W., \& Park, D. C. (1998). Effects of age and training formats on basic computer skill acquisition in older adults. Educational Gerontology, 24, 326. 
Economist (2001). How countries go high-tech. Economist, 361, 12-15.

Elias, P. K., Elias, M. F., \& Robbins, M. A. (1987). Acquisition of word-processing skills by younger, middle-age, and older adults. Psychology and Aging, 2, 340-348.

Evans-Cowley, J. \& Marita Conroy, M. (2006) The growth of e-government in municipal planning1. Journal of Urban Technology, 13, 81-107.

Garfein, A. J., Schaie, K. W., \& Willis, S. L. (1988). Microcomputer proficiency in later middle-aged and older adults: Teaching old dogs new tricks. Social Behavior, 3, $131-148$.

Garrison, D. (2000). The 'net' generation. Women in Business, 52, 14-18.

Gates, B. (2008). The tech revolution has just begun. PC Magazine, 27, 74-75.

Geffen, M., \& Kost, J. (2006). How technology enables transformation of human service administration. Policy \& Practice of Public Human Services, 64, 14-17.

General Accounting Office (2007). GAO reveals e-gov successes, failures. Government Procurement, 12, 43-43.

Gilly, M. C. \& Zeithaml, V. A. (1985). The elderly consumer and adoption of technologies. The Journal of Consumer Research, 12, 353-357.

Gist, M., Rosen, B., \& Schwoerer, C. (1988). The influence of training method and trainee age on the acquisition of computer skills. Personal Psychology, 41, 255265.

Government Executive. (2001). Surfers of the next wave. Government Executive, 33, 5151.

Grenier, A. M. (2007). Crossing age and generational boundaries: Exploring intergenerational research encounters. Journal of Social Issues, 63, 713-727. 
Gronbach, K. (2000). Generation Y - Not just kids. Direct Marketing, 63, 36-39.

Hartley, A. A., Hartley, J. T., \& Johnson, S. A. (1984). The older adult as computer user. In P. K. Robinson, J. Livingston, \& J. E. Birren (Eds.), Aging and technology advances (pp. 347-348). New York: Plenum.

Hart-Teeter (2003). The new e-government equation: Ease, engagement, privacy \& protection. The Council for Excellence in Government, 1-33.

Ho, A. T. (2002). Reinventing local governments and the e-government initiative. Public Administration Review, 62, 434-444.

Holden, S. H. \& Millett, L. I. (2005). Authentication, privacy, and the federal EGovernment. The Information Society, 21, 367-377.

Hughes, V. (2003) 'From managerialism to empowerment in human services', in Moving Beyond Managerialism in Human Services, eds L. Briskman \& M. Muetzelfeldt, RMIT Publishing, Melbourne.

Hutchinson, D., Eastman, C., \& Tirrito, T. (1997). Designing user interfaces for older adults. Educational Gerontology, 23, 497-513.

Jaeger, P. T. (2004). The social impact of an accessible e-democracy. Journal of Disability Policy Studies, 15, 19-26.

Jain, A., Mandviwalla, M., Banker, R. D. (2007). Government as catalyst: Can it work again with wireless internet access? Public Administration Review, 67, 993-1005.

James, J. (2005). The global digital divide in the internet: Developed countries constructs and Third World realities. Journal of Information Science, 31, 114-123. 
Janssen, D., Rotthier, S., \& Snijkers, K. (2004). If you measure it they will score: An assessment of international eGovernment benchmarking. The International Journal of Government \& Democracy in the Information Age, 9, 121-130.

Kelley, C., \& Charness, N. (1995). Issues in training older adults to use computers. Behavior \& Information Technology, 14, 107-120.

Kenny, C. (2002). Information and communication technologies for direct poverty alleviation: Costs and benefits. Development Policy Review, 20, 141-158.

Kerschner, P. A., \& Hart, K. C. (1984). The aged user and technology. In R. E. Dunkle, M. R. Haug, \& M. Rosenberg (Eds.), Communication technology and the elderly (pp. 135-144). New York: Springer.

Koontz, L. (2007). Homeland security: DHS privacy office has made progress but faces continuing challenges: GAO-07-1024T. GAO Reports, 1-28.

Kunstelj, M. \& Vintar, M. (2004). Evaluating the progress of e-government development: a critical analysis. International Journal of Government \& Democracy in the Information Age, 9, 131-148.

Lawhon, T., Ennis, D., \& Lawhon, D. C. (1996) Senior adults and computers in the 1990s. Educational Gerontology, 22, 193-201.

Lee, M. (2006). The history of municipal public reporting. International Journal of Public Administration, 29, 453-476.

Lenhart, A. 2000. Who's not online: $57 \%$ of those without Internet access say they do not plan to log on. Pew Internet and American Life Project. Washington, D.C: Pew Foundation. 
Lin, D. M. (2003). Age differences in the performance of hypertext perusal as a function of text topology. Behaviour and Information Technology, 22, 219-227.

Lundquist, E. (2007). A technology renaissance. eWeek, 24, 6-6.

McDaniel, S. A. (2002). Information and communication technologies: Bugs in the generational ointment. Canadian Journal of Sociology, 27, 535-547.

McMullin, J. A., Duerden Comeau, T., \& Jovic, E. (2007). Generational affinities and discourses of difference: A case study of highly skilled Information Technology workers. British Journal of Sociology, 58, 297-316.

Melenhorst, A., Rogers, W. A., Bouwhuis, D. G. (2006). Older adults' motivated choice for technological innovation: Evidence for benefit-driven selectivity. Psychology and Aging, 21, 190-195.

Millard, J., Iversen, S. J., Kubicek, H., Westholm, H. \& Cimander, R. (2004) Reorganisation of Government Back Offices for Better Electronic Public Services -European Good Practices (Back-office Reorganisation): Final Report to the European Commission, Main Report.

Moe, T. M. (Ed.). (1995). Private vouchers. Stanford, CA: Hoover Institution Press. Moon, M. J. (2002). The evolution of E-Government among municipalities: Rhetoric or reality? Public Administration Review, 62, 424-433.

Moon, M. J. \& Welch, E. W. (2005) Same bed, different dreams? A comparative analysis of citizen and bureaucrat perspectives on e-government. Review of Public Personnel Administration, 25, 243-264. 
Morrell, R. W., Park, D. C., Mayhorn, C. B., \& Kelley, C. L. (2000). Effects of age and instructions on teaching older adults to use ELDERCOMM, an electronic bulletin board. Educational Gerontology, 26, 221-235.

Morris, D.C. (1989). A survey of age and attitudes toward computers. Journal of Educational Technology Systems, 17, 73-78.

Moulder, E. (2001). E-government... If you build it, will they come? Public Management, 8, 10-15.

Myerson, I, Hale, S., Wagstaff, D, Poon, L. W, \& Smith, G. A. (1990). The informationloss model: A mathematical theory of age-related cognitive slowing. Psychological Review, 97, 475-487.

Norris, D. F., \& Moon, M. J. (2005). Advancing e-government at the grassroots: Tortoise or hare? Public Administration Review, 65, 64-57.

Osborne, D., \& Gaebler, T. (1992). Reinventing government. New York: Plume.

PA Times. (2003) E-government study finds ease, engagement, privacy, protection are top priorities. PA Times, 26, 1-2.

PA Times. (2007). Senior public servants say better service a priority. PA Times, 30, 1-2.

Peters, B. G. (2001). The future of governing (2nd ed.). Lawrence: University Press of Kansas.

Peters, B. G., \& Pierre, J. (1998). Governance without government? Rethinking public administration. Journal of Public Administration Research and Theory, 8, 223243.

Pierre, J. (Ed.). (1995). Bureaucracy in the modern state: An introduction to comparative public administration. Brookfield, VT: Elgar. 
Posner, M. (2007). Expert says United States is now engaged in a cyber war. CongressDaily, 9-9.

Prince, B. (2007). Feds get low mark on cyber-security. eWeek, 24, 14-14.

Qureshi, Sajda. (2005). E-government and IT policy: Choices for government outreach and policy making. Information Technology for Development, 11, 101-103.

Richards, J. (2006) Government needs to build trust to drive use of e-services, say IT heads. Computer Weekly, 52-52.

Riley, T. B. (1997). Privacy in the digital age. PA Times, 20, 1-4.

Roberts-Witt, S. L. (2000). The internet generation. Interactive Week, 7, 120-122.

Rogers, J. (2003, July 7). Cost of e-government work soars. Computer Weekly. Retrieved March 10, 2008, from http://www.computerweekly.com/Articles/2003/07/07/195785/cost-of-egovernment-work-soars.htm

Rossi, J. (2007). What generation gap? T+D, 61, 10-11. Salthouse, T. A., Legg, S., Palmon, R., \& Mitchell, D. (1990). Memory factors in age-related differences in simple reasoning. Psychology and Aging, 5, 9-15.

Schwartz, K. D. (2005). Eye of security. Government Executive, 37, 73-74.

Slack, F., \& Rowley, J. E (2004). Challenges in the delivery of e-government through kiosks. Journal of Information Science, 30, 369-377.

Smith, M. W., Sharit, J., \& Czaja, S. J. (1999). Aging, motor control, and the performance of computer mouse tasks. Human Factors, 41, 389-396.

Sobie, R. J. (2003). E-Government accessibility for persons with disabilities. PA Times, $26,7-7$. 
Stoltz-Loike, M., Morrell, R. W., \& Loike, J. D. (2005). Usability testing of BusinessThinking TM e-learning CD-ROMs with older adults. Educational Gerontology, 31, 765-786.

Strohm, C. (2007). Department exposed to security breaches. CongressDaily, 2-2.

Thomas, C. (1998). Maintaining and restoring public trust in government agencies and their employees. Administration \& Society, 30, 166-193.

Tolbert, C. J. \& Mossberger, K. (2006). The effects of e-government on trust and confidence in government. Public Administration Review, 66, 354-369.

Trentin, G. (2003) E-learning and the third age. Journal of Computer Assisted Learning, 20, 21-30.

Von Haldenwang, C. (2004) Electronic government (E-Government) and development. European Journal of Development Research, 16, 417-432.

Walker, N., Philbin, D. A., \& Fisk, A. D. (1997). Age-related differences in movement control: Adjusting submovement structure to optimize performance. Journal of Gerontology, 52, 40-52.

West, D. M. (2004). E-government and the transformation of service delivery and citizen attitudes. Public Administration Review, 64, 15-27.

Wilhelm, T., Carmen, D., \& Reynolds, M. (2002). Kids count snapshot. Connecting kids to technology: Challenges and opportunities. Baltimore, MD: Annie E. Casey Foundation.

Wilshusen, G. C. (2007) Cyber insecurity. FDCH Congressional Testimony. 
Ya Ni, A., \& Bretschneider, S. (2007). The decision to contract out: A study of contracting for e-government services in state governments. Public Administration Review, 67, 531-544.

Zandri, E. \& Charness, N. (1989). Training older and younger adults to use software. Educational Gerontology, 15, 615-631. 


\section{APPENDIX A}

\section{Survey Cover Letter}

\section{Dear Respondent,}

I am a doctoral candidate at West Virginia University, and I am inviting you to participate in a research project to study the effects of demographic characteristics and expertise on public administrators' e-government attitudes. Attached is a short questionnaire that asks a variety of questions about e-government. Please go over the questionnaire and, if you choose to do so, complete it and send it back to me in the return envelope enclosed in this package.

The results of this project will be the data for my dissertation on public administration. Through your participation I hope to understand the factors that affect the attitudes of public administrators to e-government. I hope that the results of the survey will be useful for the administrative discourse community and future researchers, and I hope to share my results by publishing them in my dissertation.

I do not know of any risks to you if you decide to participate in this survey and your responses will be kept as confidential as legally possible. I promise not to share any information that identifies you with anyone outside my research group which consists of me and Dr. Patricia Obenauf (West Virginia University).

The survey should take you about 5 minutes to complete. I hope you will take the time to complete this questionnaire and return it. Your participation is voluntary, and there are no negative affects if you do not participate. Regardless of whether you choose to participate, please let me know if you would like a summary of my findings. To receive a summary, please send me an e-mail or indicate your interest in the findings as indicated on the survey.

If you have any questions or concerns about completing the questionnaire or about being in this study, you may contact me by e-mail at ralshara@mix.wvu.edu or by telephone at (304) 216-7755. West Virginia University's Institutional Review Board (IRB) acknowledgment of this study is on file.

Sincerely,

Raji AlSharari

Doctoral Candidate West Virginia University 


\section{APPENDIX B}

\section{Perceptions of E-technology and E-government}

E-government (Electronic Government)- A generic term for Web-based services from agencies of local, state, and federal governments.

1. Expertise: Please circle the item that indicates your expertise with this electronic technology. ( $A=$ No skills at all, $B=B e g i n n e r, C=$ Intermediate, $D=A d v a n c e d$ )
(a) Building a website:
A $\quad$ B $\quad C \quad$ D
(b) Updating a website:
A $\quad$ B $\quad C \quad$ D
(c) Web search engines:
A $\quad$ B $\quad C \quad$ D
(d) Downloading files:
A $\quad$ B $\quad C \quad$ D
(e) Uploading files:
A $\quad$ B $\quad C \quad$ D
(f) Building a local network:
A $\quad$ B $\quad C \quad$ D
(g) Updating a local network:
A $\quad$ B $\quad$ C $\quad$ D
(h) Voice activate cell phones:
A $\quad$ B $\quad C \quad$ D
(i) Voice response computer software:
A $\quad$ B $\quad C \quad$ D
(j) Voicemail:
A $\quad$ B $\quad C \quad$ D
(k) E-mail:
A $B \quad C \quad D$
(l) Instant messaging:
A B C
(m) Internet chat:
A $\quad$ B $\quad$ C $\quad$ D
(n) Blogs:
A $\quad$ B $\quad$ C $\quad$ D

2. Please mark the item that represents how comfortable you are with e-government. $\square$ Not comfortable $\square$ Somewhat comfortable $\square$ Comfortable $\square$ Very comfortable

3. Overall, how would you describe the effect that e-government has on the way that government works?

$\square$ Very positive $\square$ Somewhat positive $\square$ Somewhat negative $\square$ Very negative

4. Looking ahead $\mathbf{5}$ to $\mathbf{1 0}$ years, describe the effect that you think e-government will have on the way that government operates?

$\square$ Very positive $\square$ Somewhat positive $\square$ Somewhat negative $\square$ Very negative

5. Overall, would you say that e-government is developing
$\square$ Too slowly
$\square$ Slowly
$\square$ Quickly
$\square$ Too quickly

6. How would you describe the amount of resources available for e-government?
$\square$ Excessive
$\square$ Adequate
$\square$ Barely enough
$\square$ Insufficient 
7. How would you describe the availability of e-government services for the public?
$\square$ Excessive
$\square$ Adequate
$\square$ Barely enough
$\square$ Insufficient

8. How would you describe the security in government technology at this time?
$\square$ Excessive
$\square$ Adequate
$\square$ Barely enough
$\square$ Insufficient

9. How would you describe the assessments of e-government services at this time?
$\square$ Excessive
$\square$ Adequate
$\square$ Barely enough
$\square$ Insufficient

10. How would you describe the training of personnel to use e-government technology?
$\square$ Excessive
$\square$ Adequate
$\square$ Barely enough
$\square$ Insufficient

11. Please list any potential barriers you see for e-government at this time:
a.
b.
c.

12. Type of Administration:

$\square$ Municipality

$\square$ County

13. Year of birth:

14. Gender:
$\square$ Female
$\square$ Male

\section{Education:}
$\square$ High School Diploma
$\square$ Technical/Vocational School
$\square$ Some College
$\square$ 2-year College Degree
$\square$ 4-year College Degree
$\square$ Master's Degree
$\square$ Some Doctorate Courses
$\square$ Doctorate Degree
$\square$ Other:

16. Field of Education:
$\square$ Liberal Arts
$\square$ Business/Economics
$\square$ Public Administration
$\checkmark$ Political Science
$\square$ Engineering
$\checkmark$ Other:

Thank you for taking the time to fill out this survey. Please return the survey in the enclosed envelope. 
PO Box 618

Ripley, WV 25271

Education

\section{Raji M. AlSharari}

Phone: (540)-449-9354

Email: nawashmal@yahoo.com
Aug. 2007-Dec.2011 West Virginia University Morgantown, WV Doctor of Education, Curriculum \& Instruction

May 2006-May 2008 West Virginia University Morgantown, WV Master of Public Administration

Aug. 1998-May 2002 Al Qassim University Al Qassim, Saudi Arabia Bachelor of Arts, Sociology

Employment History: The Institute of Public Administration (IPA)

Aug. 2009-Nov. 2010

July 2008-Aug. 2009

Jan. 2005-April 2005

March 2004-Dec. 2004

Nov. 2003- Feb. 2004

Jan. 2003-Oct. 2003
Program Coordinator/Instructor

Organizational Behavior Sector

IPA, Riyadh, Saudi Arabia

Instructor of PA Courses

Administrative Programs Department

IPA, Riyadh, Saudi Arabia

Survey Designer \& Research Assistant

Research Center Department

IPA, Riyadh, Saudi Arabia

Seminar Coordinator

Seminars and Symposium Department

IPA, Riyadh, Saudi Arabia

Member in Ministerial Committee Department

IPA, Riyadh, Saudi Arabia

Member in Planning and Developing Department

IPA, Riyadh, Saudi Arabia $\underline{\text { Publications }}$

Languages

Computer Skills

$\underline{\text { Memberships }}$
The Custodian of the Two Holy Mosques King Abdullah bin Abdulaziz: Comprehensive Vision in Managing Development (2009) (IPA co-author)

Arabic

English

MS Word, Powerpoint, Excel, Internet Explorer, Adobe Acrobat, search engines, research portals, SPSS

Student Association of Public Administrators (SAPA), 2006-2008 International City/County Management Association(ICMA), 2008 